\title{
Data Collection in Sensor Cloud: Recent Advances, Taxonomy, Use Cases and Open Challenges
}

\author{
IHSAN ALI ${ }^{1}$, \\ ${ }^{1}$ Department of Computer System \& Technology, Faculty of Computer Science \& Information Technology, University of Malaya, Malaysia \\ Corresponding authors: Ihsan Ali \\ (e-mail:ihsanalichd@siswa.um.edu.my)
}

\begin{abstract}
BABSTRAGT In recent years, Wireless Sensor Networks (WSNs) technologies are used in many important areas, including weather forecasting, security, environmental monitoring, health care, and industry. Nonetheless, due to the constraints of WSNs in terms of energy, processing, connectivity, computation and data integrity. An important issue in this research field is the efficient management of the large number of WSN's data. Therefore, there is a need for strong and scalable high-performance computing and large storage infrastructure for real-time processing and storage of WSN's data. This article attempts to discuss data collection methods in WSNs, sensor cloud, and IoT. Also, in this context, a general overview of WSNs and sensor cloud platforms, including their definitions, architectures, and applications are given. We investigate, highlight and report recent advances in data collection technology by categorizing and classifying data collection methods in WSNs, sensor cloud, IoT and developing a taxonomy based on these classifications. Furthermore, the analysis and synthesis of existing works in this research domain is highlighted. The identification of key research challenges for future work and use case in this research domain were also highlighted and discussed.
\end{abstract}

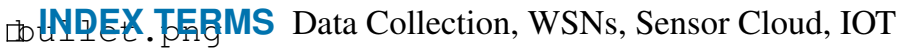

\section{INTRODUCTION}

$\mathbf{R}$ ECENTLY sensor cloud has been utilized in many sensor networks to collect, store, and processed large amount of data, particularly on sensor networks that produced a lot of data. Hence, the stored and processed data can be viewed and monitored by end users remotely [1] Various applications such as transportation, businesses, healthcare, border protection, weather forecasting, and so on, generate large volume of data. This data needed to be collected, retained and processed before final decision are made. Therefore, in most of the cases the resources are deficient for examining and storing the data for future use. With the developments in Wireless Sensor Networks (WSNs), it will be beneficial if sensor data can be uploaded to online communities, forums, and social network applications [2], [3]. This revolution would help to be useful for the techniques developed for emerging cloud computing, data taken from sensor networks from information-needed applications. Highperformance computing methods may usually be replaced or find a room in data processing before the data is transmitted to the cloud [2]. In this paper, a review on data collection in WSNs, sensor cloud, and IoT is presented. Studies published in the last decade (2009 - 2019) were considered so as to aid new and veteran researchers in understanding literature in the field of study. Our contribution lies solely in a detailed analysis and review of relevant studies in the research domain. The study seeks to explore data collection schemes in WSNs, sensor cloud, IoT, and routing protocols for data collection. With this in mind, Figure 5 represent a general taxonomy of data collection in Section V. In addition, a bibliometric overview is also presented. The bibliometric overview will aid researchers in knowing the vital publication channels, publication sources, supported grants, most active countries, and the most active institutions in the field of study. Moreover, the application scenario of data collection in different models are presented. Lastly, open challenges and future directions are given. This paper complements our own short tutorial paper [3] with the main contributions listed below.

- A comprehensive review of data collection in WSNs, 


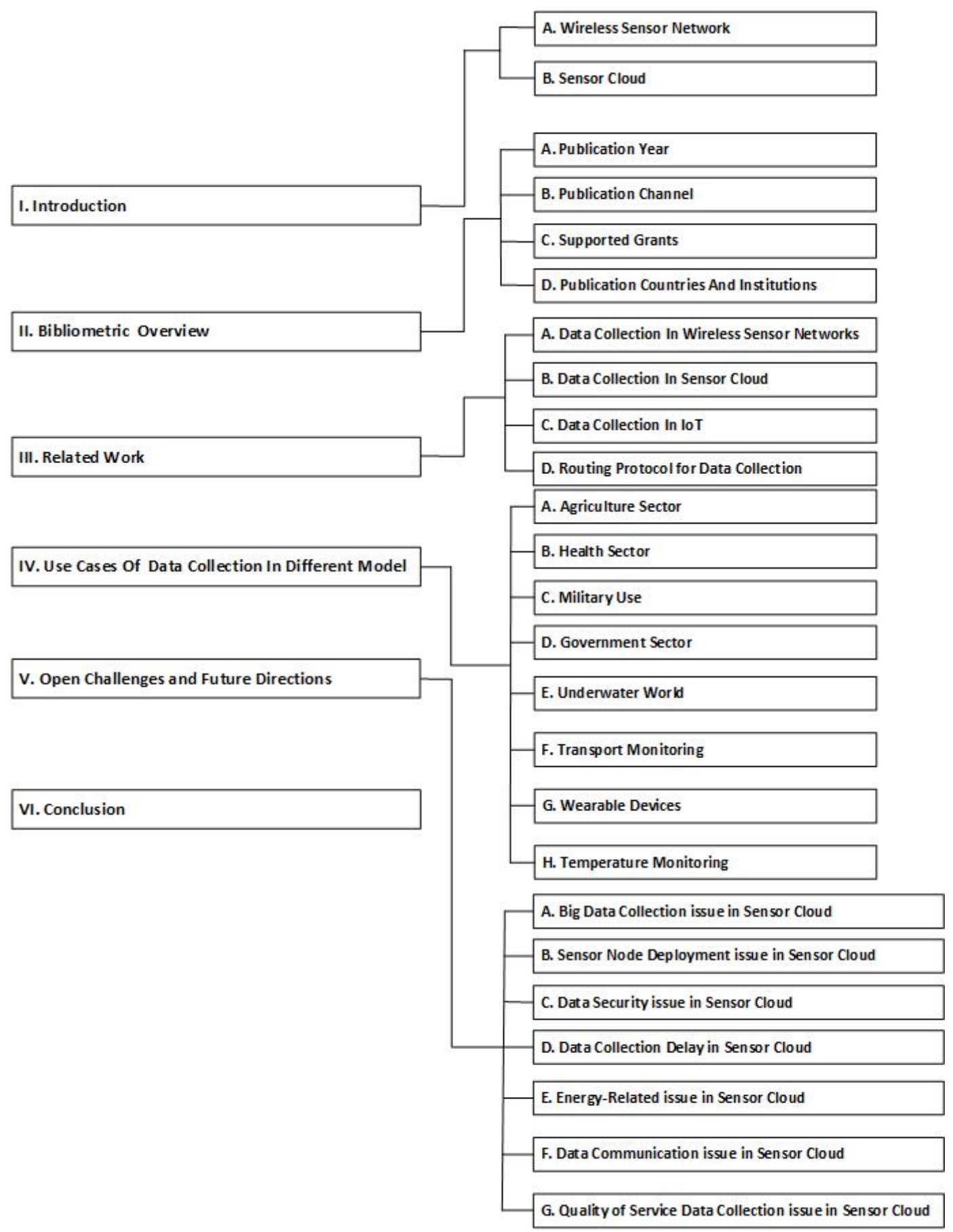

FIGURE 1: Organization of the paper 
sensor cloud, and IoT.

- The analysis and synthesis of existing works in this research domain.

- The identification of key use cases works in this research domain.

- The identification of key research challenges and directions for future work.

From table 1, we identified eight survey/review papers on data collection in WSNs. This paper is compared with the existing survey/review papers in terms of their contributions. From the table, we observed that none of the existing survey/review papers work on data collection in sensor cloud, data collection in IoT, use cases of data collection, and bibliometric overview in the field of study. Therefore, this review paper tempts to fill this research gap. The paper is structured into nine sections: Section II highlights the bibliometric overview of the relevant studies. Section III presents the literature. Hence, Data collection in WSNs, sensor cloud, and IoT are presented. In Section IV, routing protocols for data collection are outlined. Section V gives the general taxonomy for data collection. Use cases of data collection in different models are presented in Section VI. Section VII gives the open challenges and future directions. Lastly, the study is concluded in Section VIII.

\section{A. WIRELESS SENSOR NETWORKS}

In this section, a brief introduction is presented on WSNs and its applications. WSN is a type of Sensor network that is composed of sensor nodes. These sensor nodes are self-directed, small, and low-powered which are sometime called mote. Hence, these nodes work collectively in order to achieve a specific task. In WSN, each sensor node comprised of four things, which are battery, microcontroller, a commutation unit, and can accommodate multiple sensors. Moreover, these sensor nodes retrieved data from the deployed environment and then transfer it to the gateway using single or multiple hop data transmission modes.

WSNs is utilized in many areas, such as military operations, habitat monitoring, healthcare, home automation, battlefield surveillance, agriculture sector, and much more. In such an application, the sensor nodes should be flexible so that it can perform better in any condition and situation. In WSN, different techniques of data collection are used to collected data from different nodes, and the collected data is disseminated in the whole network. Moreover, the whole network is controlled by a central station. Hence, the nodes collect data and send the data to the central station for processing. In this case, relay nodes can be utilized to forward part of data to the control station.

WSNs comprised of sensor nodes that are spatially distributed. These nodes are able to sense the environmental surroundings i.e., sound, pressure, temperature, motion, vibration, and so on. WSNs are generally a major focus for researcher because of their significant application in the areas of industry, civilian, and military. Hence, traditional ways that people used in interacting with the physical world has changed. For example, with regards to forest fire detection, because sensor nodes can be purposefully and heavily deployed in a forest, the precise cause of a forest fire can be communicated to the users before the forest fire is uncontainable. Additionally, with regards to battlefield surveillance and monitoring, as sensor nodes can be deployed to unceasingly monitor the state of dangerous landscapes, paths and straits in a battlefield, and approach routes. Hence, the actions of the opposing armies can be monitored in a surveillance hub without the participation of physical scouts.

\section{B. SENSOR CLOUD}

As defined by IntelliSys, sensor cloud is: "An infrastructure that allows truly pervasive computation using sensors as an interface between physical and cyber worlds, the datacompute clusters as the cyber backbone and the internet as the communication medium" [4]. Moreover, according to Micro Strains, sensor cloud is a different sensor data storage, visualization, and remote management platform that makes use of strong cloud computing technologies to deliver exceptional data scalability, rapid visualization, and user programmable analysis [2], [12]. Sensor cloud is getting more attention from academic and industrial communities, which is essentially a new paradigm driven by incorporating the pervasive data collection abilities of WSNs and its strong data storage and processing capabilities. In Figure 1, sensor network provider (SNP), cloud service provider CSP), and cloud service user (CSU) are all contained within sensor cloud.

The SNP provides diverse forms of sensor nodes, which are static sensors, mobile sensors, and video sensors to form the WSN so as to collect many sensory data like humidity, temperature, sound, motion, vibration, and pressure of the environment. The CSP offers the strong cloud which is comprised of data centers, storing and processing the sensory data collected from the WSN. In this entire process, the SNPs act as the sensory data sources for CSPs. CSUs are the sensory data requesters for CSPs. With sensor cloud, there are many of merits [12], [13] ,helping the users,WSN, and the cloud. For example, access to the sensory data can be given to end users from the cloud anytime and in any location if there is network connection, instead of being static in one location. The efficacy of WSN can be improved through its ability to serve more than one application by the cloud. The services the cloud offers can be significantly improved by offering the services that the WSNs provides, such as environmental checking, healthcare checking, landslide detection, forest fire detection, and so on. Nevertheless, sensor cloud is still in its beginning and a great deal of research efforts are anticipated to arise in this area in years to come.

\section{BIBLIOMETRIC OVERVIEW}

In this section, the bibliometric analysis of the selected papers from the last ten years is presented. Hence, four aspects of the selected articles were examined: publication 
TABLE 1: Contributions of the Existing Surveys

\begin{tabular}{|c|c|c|c|c|c|c|c|c|c|c|c|}
\hline 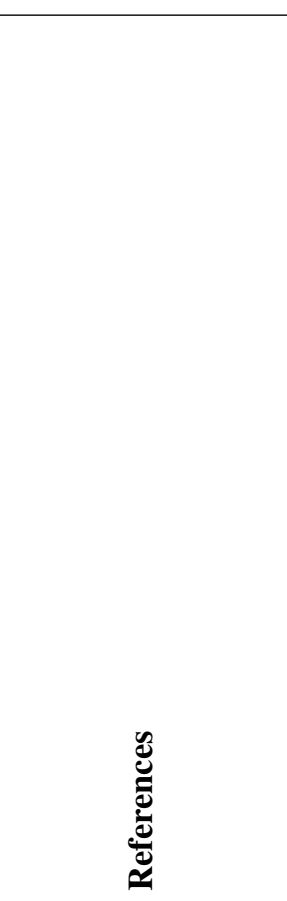 & 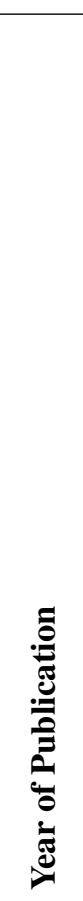 & 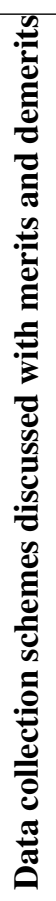 & 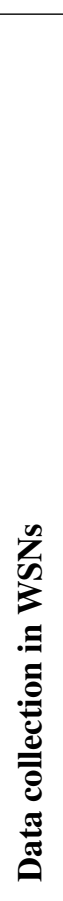 & 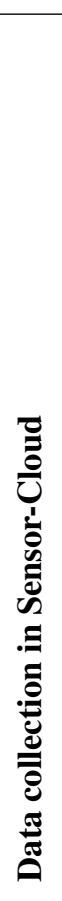 & 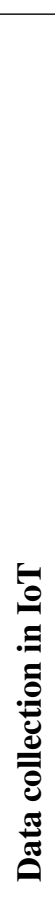 & 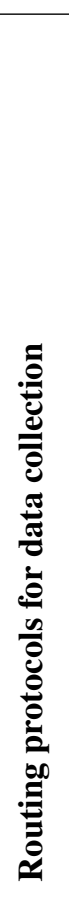 & 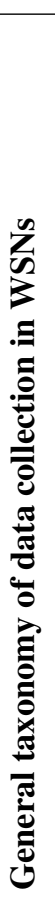 & 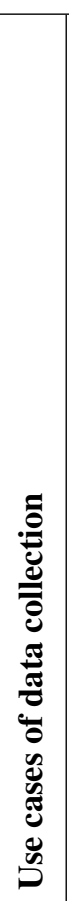 & 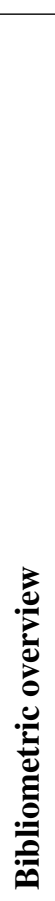 & 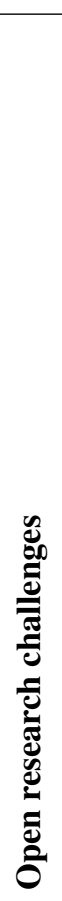 & 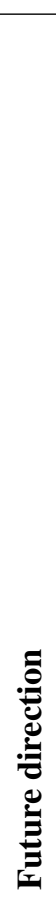 \\
\hline Singh et al. [4] & 2019 & $\checkmark$ & $\checkmark$ & $\mathrm{x}$ & $\mathrm{x}$ & $\checkmark$ & $\mathrm{x}$ & $\mathrm{x}$ & $\mathrm{x}$ & $\mathrm{x}$ & $\checkmark$ \\
\hline Wankhade et al. [5] & 2013 & $\checkmark$ & $\checkmark$ & $\mathrm{x}$ & $\mathrm{x}$ & $\mathrm{x}$ & $\mathrm{x}$ & $\mathrm{x}$ & $\mathrm{x}$ & $\mathrm{x}$ & $\mathrm{x}$ \\
\hline Khan et al. [6] & 2014 & $\checkmark$ & $\checkmark$ & $\mathrm{x}$ & $\mathrm{x}$ & $\mathrm{x}$ & $\checkmark$ & $\mathrm{x}$ & $\mathrm{x}$ & $\mathrm{x}$ & $\checkmark$ \\
\hline Francesco et al. [7] & 2011 & $\checkmark$ & $\checkmark$ & $\mathrm{x}$ & $\mathrm{x}$ & $\checkmark$ & $\mathrm{x}$ & $\mathrm{x}$ & $\mathrm{x}$ & $\mathrm{x}$ & $\mathrm{x}$ \\
\hline Yetgin et al. [8] & 2017 & $\checkmark$ & $\checkmark$ & $\mathrm{x}$ & $\mathrm{x}$ & $\mathrm{x}$ & $\mathrm{x}$ & $\mathrm{x}$ & $\mathrm{x}$ & $\mathrm{x}$ & $\checkmark$ \\
\hline Hasan et al. [9] & 2017 & $\checkmark$ & $\checkmark$ & $\mathrm{x}$ & $\mathrm{x}$ & $\checkmark$ & $\mathrm{x}$ & $\mathrm{x}$ & $\mathrm{x}$ & $\checkmark$ & $\mathrm{x}$ \\
\hline Kamlesh et al. [10] & 2014 & $\mathrm{x}$ & $\checkmark$ & $\mathrm{x}$ & $\mathrm{x}$ & $\checkmark$ & $\mathrm{x}$ & $\mathrm{x}$ & $\mathrm{x}$ & $\mathrm{x}$ & $\checkmark$ \\
\hline Nair et al. [11] & 2013 & $\checkmark$ & $\checkmark$ & $\mathrm{x}$ & $\mathrm{x}$ & $\checkmark$ & $\mathrm{x}$ & $\mathrm{x}$ & $\mathrm{x}$ & $\mathrm{x}$ & $\mathrm{x}$ \\
\hline This Survey & & $\checkmark$ & $\checkmark$ & $\checkmark$ & $\checkmark$ & $\checkmark$ & $\checkmark$ & $\checkmark$ & $\checkmark$ & $\checkmark$ & $\checkmark$ \\
\hline
\end{tabular}

year, publication channel, supported grants, and publication countries.

\section{A. PUBLICATION YEAR}

In the last decade (2009 - 2019), 84 articles were published that addressed the issue of data collection. Figure 2 highlights the evolution of publication in the literature. The research activity in this domain is progressive, particularly in the last six years $(2014-2019)$. The interest in this research area has high momentum from the year 2016 with 12 publications, respectively. This interest is partially due to the need to address data collection issues in WSNs (high energy consumption and data loss) [14] [15] [16] and also the introduction of sensor-cloud [2], [12], [13].

\section{B. PUBLICATION CHANNEL}

This section gives result about the top ten most represented Journals from our selected studies. Hence, we have also categorized the selected studies based on Journals, Conferences, and Book sections. From Figure 3, We have identified 34 articles published in Journals, 25 articles published in Conference, and one article published in Book section [14].
Moreover,table2 highlights the top ten most represented Journals and the articles that were published therein, respectively. However, the top ten Conferences were not listed because all the conferences identified in this study have only one paper published in them, respectively. Therefore, there is no need for ranking them. From the table (Table 2 ), IEEE ACCESS and IEEE Internet of Things were the most contributors with 7 and 4 articles, respectively.

\section{SUPPORTED GRANTS}

In various research areas, there can be many research supporting agencies that provide grants to researchers for a defined field in various countries. Research in data collection is also supported by different agencies. Hence, Table 3 highlights in detail all the identified funding agencies and their respective grants from the selected studies. We have identified 46 active funding agencies in this research domain with some agencies sponsoring various grants as shown in Table 3. We observed that China contributes the most with $22(47.8 \%)$ funding agencies out of 46 . Therefore, in this context, China has made a significant contribution in terms of finances in comparison to other contributing countries. 


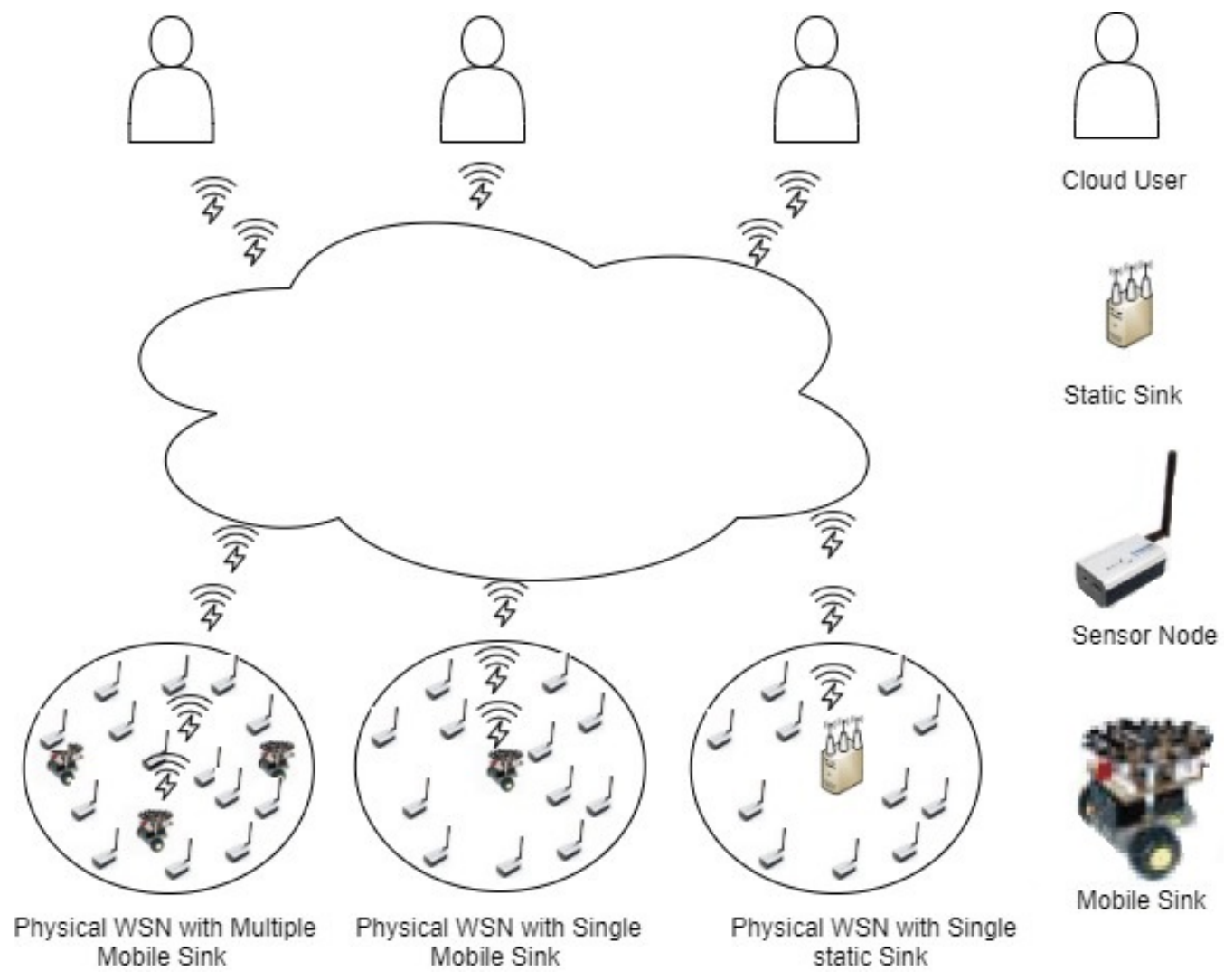

FIGURE 2: Sensor Cloud Description

TABLE 2: Top 10 Most Represented Journals

\begin{tabular}{|c|c|c|}
\hline Publisher & Journal Name & Papers \\
\hline IEEE & IEEE ACCESS & {$[2][17][18][19][20][21][22]$} \\
\hline IEEE & IEEE Internet of Things Journal & {$[23][24][25][26]$} \\
\hline Elsevier & AEU-International Journal of Electronics and Communications & {$[16][27][28][29][30]$} \\
\hline MDPI & Sensors & {$[31][32][33][34]$} \\
\hline Elsevier & Ad hoc Networks & {$[35][36][37]$} \\
\hline Elsevier & Future Generation Computer Systems & {$[13][38][39]$} \\
\hline IEEE & IEEE Transactions on Mobile Computing & {$[40][41][42]$} \\
\hline Hindawi & Wireless Communications and Mobile Computing & {$[43][44]$} \\
\hline Elsevier & Information Sciences & {$[1][45]$} \\
\hline Elsevier & Computer Networks & {$[46][47]$} \\
\hline
\end{tabular}

\section{PUBLICATION COUNTRIES AND INSTITUTIONS}

In this section, information about countries and institutions that made more contribution in terms of papers output is presented. We have identified 24 countries that are active in the research domain. Table 4 presents the top ten most active countries with the most output (in terms of papers) in the research domain. From Table 4, we observed that China is the most active country which contributed the most papers in the research domain with 43 papers. Followed by USA and India with 14 and 10 papers, respectively.

Table 5 shows the top ten most active institutions in the research domain with respect to their number of publications. From our selected studies, we have identified 93 active institutions from different countries. Most of these institutions are academic centric with few studies as collaborative works between academic institutions and industrial labs [47]. Huaqiao University with 9 papers has the highest number of publications. Followed by Central South University and Zhenjiang University with 7 and 6 publications each. Moreover, we observed that all the top 10 universities are academic institutions. Looking at the table (Table 5), it is not a surprise to see that seven out of the top ten institutions are all from China. Because from Table 4, we observed that China contribute almost $50 \%$ of the studies in this domain for the last ten years. 
TABLE 3: Details about Funding Agencies and their grant

\begin{tabular}{|c|c|c|c|}
\hline $\mathbf{S} / \mathbf{N}$ & Country & Funding Agency & Grant Numbers \\
\hline 1 & China & National Natural Science Foundation of China (NSFC). & $\begin{array}{lll}61371125, & 61602305, & 61802257, \\
61571150, & 61572262, \\
61420106009, & 61572325, \\
61672536, & 61672535, & 61772559, \\
61562005, & 61572528, & 61772554, \\
6157256, & 61702089, & 61402094, \\
61471035, & 61772034, & 61772286, \\
U 1604149, & 61572206, & 61532013, \\
61632009, & 61772148, & 61672441, \\
61572172, & \mathrm{U} 1401253, & 61402405, \\
61772554, & 61602152, & 61572526, \\
61601169, & 61572528, & 60803152, \\
6157256, & 61672441,61771258 .\end{array}$ \\
\hline 2 & Taiwan & $\begin{array}{l}\text { Ministry of Science and Technology of Taiwan } \\
\text { (MOST). }\end{array}$ & $\begin{array}{l}\text { MOST105-2221-E-032-047, } \\
\text { MOST104-2221-E- } \quad 032-005, \\
\text { MOST105-2221-E-151-023, } \\
\text { MOST105- } 2221-E-151-042, \\
\text { MOST105-2221-E-151-057. }\end{array}$ \\
\hline 3 & USA & National Science Foundation(NSF). & $\begin{array}{l}\text { ITR0205671, CNS0619926, } \\
\text { CNS0626151,CCF0634803, } \\
\text { CNS1647170, CNS1450768. }\end{array}$ \\
\hline 4 & Japan & $\begin{array}{l}\text { Japan Society of the Promotion of Science (JSPS) } \\
\text { KAKENHI. }\end{array}$ & JP16K00117, JP15K15976. \\
\hline 5 & USA & Army Research Office (ARO). & $\begin{array}{l}\text { W911NF-06-1-0275, W911NF-07- } \\
\text { 2-0027. }\end{array}$ \\
\hline 6 & China & $\begin{array}{l}\text { Fundamental Research Funds for the Central Universi- } \\
\text { ties, China. }\end{array}$ & $\begin{array}{l}\text { FRF-BD-18-016A, N172304022, } \\
20161310714,2016 \mathrm{~B} 03114 .\end{array}$ \\
\hline 7 & China & $\begin{array}{l}\text { National Basic Research Program of China (973 Pro- } \\
\text { gram). }\end{array}$ & 2014CB046305, 2015CB352401. \\
\hline 8 & China & $\begin{array}{l}\text { Foster Project for Graduate Student in Research and } \\
\text { Innovation of Huaqiao University. }\end{array}$ & $1511414002,1511414005$. \\
\hline 9 & China & Natural Science Foundation of Hebei Province. & F2016501076, F2016501079. \\
\hline 10 & USA & Claremore Public Schools Foundation (CPSF). & 2015 M581934. \\
\hline 11 & Japan & KDDI Foundation. & Nil. \\
\hline 12 & $\begin{array}{l}\text { South Ko- } \\
\text { rea }\end{array}$ & National Research Foundation of Korea (NRF). & $\begin{array}{l}\text { NRF2015R1D1A1A01061155, } \\
\text { NRF2017R1D1A1B03031055. }\end{array}$ \\
\hline 13 & USA & Army AHPCRC. & $\begin{array}{l}\text { W911NF-07-02-0027, W911NF- } \\
\text { 06-1-0275. }\end{array}$ \\
\hline 14 & China & National Natural Science Foundation of P. R. China. & $61373138,61672297$. \\
\hline 15 & China & Postdoctoral Foundation. & 2015M570468, 2016T90485. \\
\hline 16 & China & Natural Science Foundation of Zhejiang Province. & LY17F020032. \\
\hline 17 & China & Sixth Talent Peaks Project of Jiangsu Province. & DZXX-017. \\
\hline \multicolumn{4}{|c|}{ Next page } \\
\hline
\end{tabular}




\begin{tabular}{|c|c|c|c|}
\hline \multicolumn{4}{|c|}{ Continue... } \\
\hline $\mathbf{S} / \mathbf{N}$ & Country & Funding Agency & Grant Numbers \\
\hline 18 & China & $\begin{array}{l}\text { Fund of Jiangsu High Technology Research Key Labo- } \\
\text { ratory for Wireless Sensor Networks. }\end{array}$ & WSNLBZY201516. \\
\hline 19 & China & $\begin{array}{l}\text { Science and Technology Innovation Fund for Postgrad- } \\
\text { uate Education of Jiangsu Province. }\end{array}$ & KYLZ15_0853. \\
\hline 20 & China & $\begin{array}{l}\text { Henan Province Education Department Cultivation } \\
\text { Young Key Teachers in University. }\end{array}$ & 2016GGJS-158. \\
\hline 21 & Australia & Australian Research Council. & DP170100136, LP140100816. \\
\hline 22 & China & $\begin{array}{l}\text { Henan Province Education Department Natural Sci- } \\
\text { ence Foundation. }\end{array}$ & 19A520006, 1913510007. \\
\hline 23 & China & $\begin{array}{l}\text { Luoyang Institute of Science and Technology High- } \\
\text { Level Research Start Foundation. }\end{array}$ & $2017 \mathrm{BZ} 07$. \\
\hline 24 & Sweden & Swedish Government Agency Vinnova. & 2015-00347. \\
\hline 25 & Qatar & Qatar National Research Fund. & NPRP-8-519-1-108. \\
\hline 26 & China & Guangzho Education Bureau Science Foundation. & 1201430560. \\
\hline 27 & $\begin{array}{l}\text { China } \\
\text { China }\end{array}$ & $\begin{array}{l}\text { Science and Technology Planning Project of } \\
\text { Guangzhou. } \\
\text { Science and Technology Program of Henan Province. }\end{array}$ & $\begin{array}{l}201707010284 . \\
192102210249,182102210428 .\end{array}$ \\
\hline 29 & China & National Key Technology Support Program . & 2015BAH16F00/F01. \\
\hline 30 & China & $\begin{array}{l}\text { National Science Foundation of Fujian Province of } \\
\text { China. }\end{array}$ & 2014J01240. \\
\hline 31 & Turkey & $\begin{array}{l}\text { Turkish National Academy of Sciences Distinguished } \\
\text { Young Scientist Award Program (TUBAGEBIP). }\end{array}$ & V.G/TUBA-GEBIP/2013-14. \\
\hline \multicolumn{4}{|c|}{ Next page } \\
\hline 32 & China & Shanghai Scientific Innovation Act of STCSM . & 15JC1402400 \\
\hline 33 & China & 985 Project of Shanghai Jiao Tong University. & WF220103001. \\
\hline 34 & China & National Science Foundation of Guangxi Province. & 2018GXNSFBA281169. \\
\hline 35 & China & $\begin{array}{l}\text { Promotion Program for Young and Middle-aged } \\
\text { Teacher in Science and Technology Research of } \\
\text { Huaqiao University. }\end{array}$ & ZQN-PY308. \\
\hline 36 & China & $\begin{array}{l}\text { Six Talented Eminence Foundation of Jiangsu } \\
\text { Province. }\end{array}$ & XYDXXJS-044. \\
\hline 37 & China & 1311 Talents Plan of NUPT. & NY217057. \\
\hline 38 & China & China Postdoctoral Science Foundation. & 2017M610252, 2017T100297. \\
\hline 39 & China & $\begin{array}{l}\text { Natural Science Foundation for Colleges and Universi- } \\
\text { ties in Jiangsu Province. }\end{array}$ & 16KJB510034, 16KJB520034. \\
\hline 40 & China & National Science Foundation of Shanghai. & 18ZR1426000. \\
\hline 41 & China & $\begin{array}{l}\text { Open Research Project of the State Key Laboratory of } \\
\text { Industrial Control Technology, Zhejiang University. }\end{array}$ & ICT1800391 \\
\hline 42 & France & ANR Program Investments for the Future. & ANR-11-LABX-0031-01. \\
\hline 43 & China & The Basic Research Project of Shenzhen. & JCYJ20150630153917254. \\
\hline 44 & China & National Science Foundation of Liaoning Province. & 201602254. \\
\hline 45 & China & $\begin{array}{l}\text { The Science and Technology Plan Project of } \\
\text { Guangzhou. }\end{array}$ & 201804010433. \\
\hline 46 & China & $\begin{array}{l}\text { The Bidding Project of Laboratory of Language Engi- } \\
\text { neering and Computing. }\end{array}$ & LEC2017ZBKT001. \\
\hline
\end{tabular}




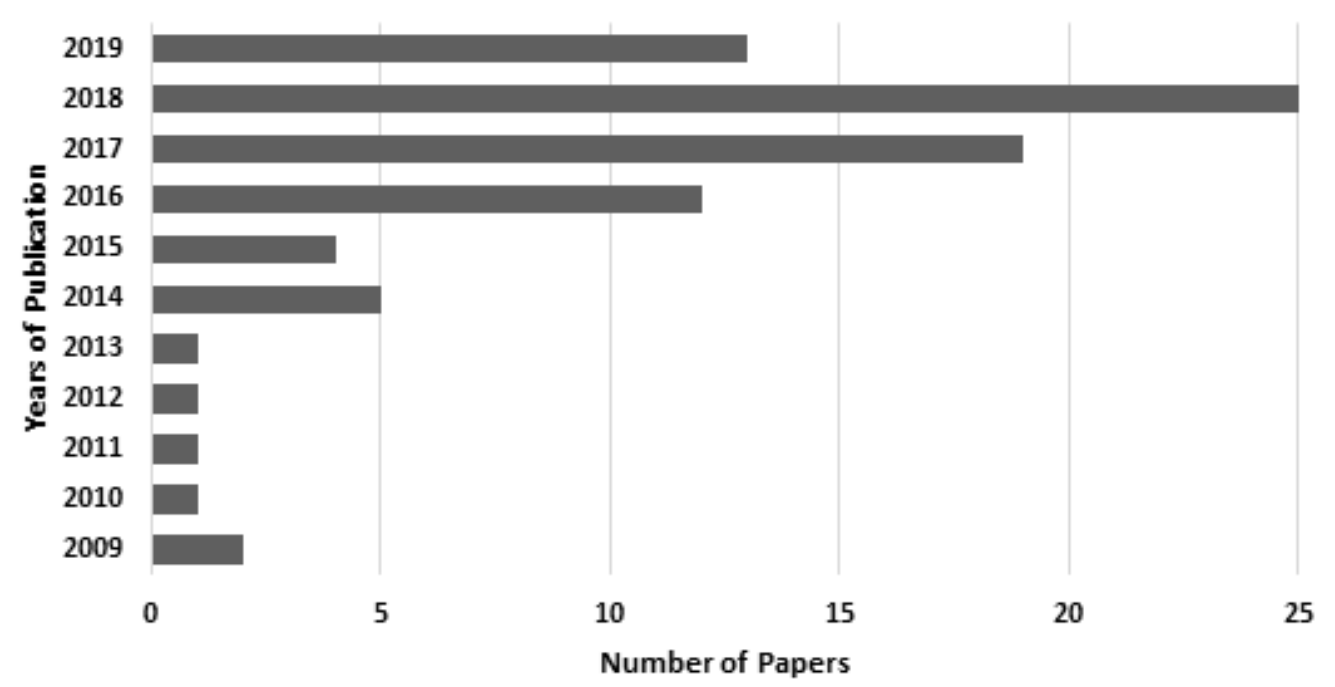

FIGURE 3: Number of Publication Per-year

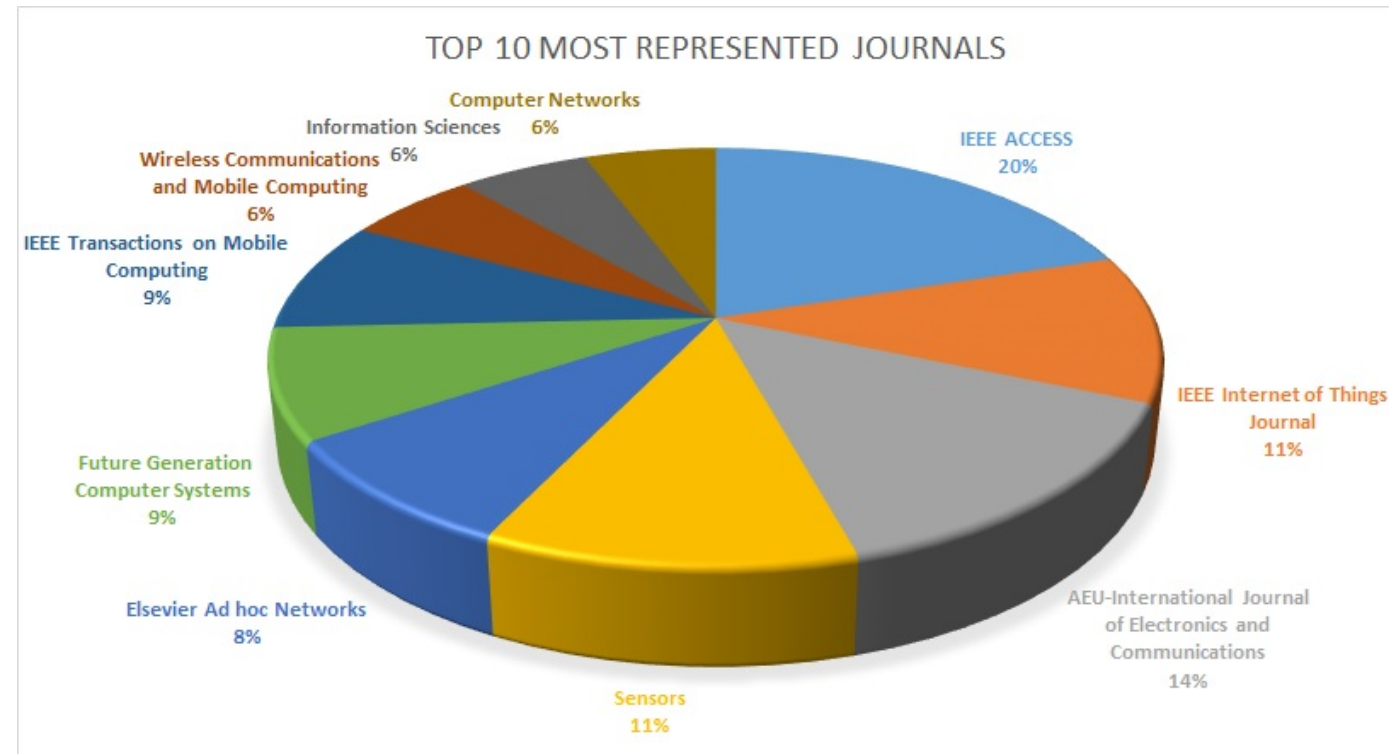

FIGURE 4: Diagrammatic Representation for Number of Publication Per-year

\section{RELATED WORK}

This section highlights the literature on data collection in WSNs, sensor cloud, and IoT. Six aspect of data collection are considered, which are data collection in WSNs using single static sink, multiple static sinks, single mobile sink, Multiple Mobile Sinks, data collection in sensor cloud, and data collection in IoT.

\section{A. DATA COLLECTION IN WIRELESS SENSOR NETWORKS (WSNS)}

In this section, we discuss studies on data collection in WSNs. Data is one of the main parameters to be collected and processed to take further action in any system. If the data is collected in proper way, then the decision on that data will be correct, otherwise the decision will be wrong which can destroy the whole system. There are different solutions (models/algorithms/frameworks) used for data collection in WSNs. In early days, data was retrieved by ordinary sensor nodes and then forward to the main sink/base station. In this model, the data flow is from the sensor node to the sink and the node near to the sink bear more load of data forwarder which will drain out their energy quickly and will create the hotspot issue in WSNs [25]. To handle this hotspot problem, the idea of Mobile Sink (MS) was introduced by [48] to distribute the load of sensor node near the sink. The mobile sink will not be placed at one fixed location, therefore, the sink will be moving to different location for data collection. In this way, the node of forwarding will be 
35

30

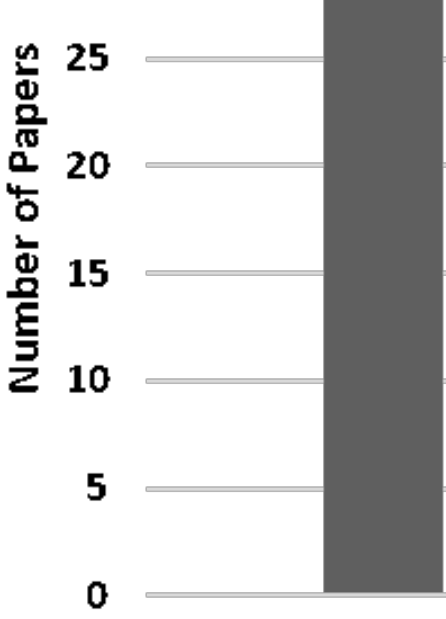

Journals

Canferences

Baak Section

\section{Sources}

FIGURE 5: Publication Sources

TABLE 4: Top 10 Countries Contributing to the Research Domain

\begin{tabular}{|c|c|c|}
\hline S/N & Countries & Numbers of Papers \\
\hline 1 & China & 43 \\
\hline 2 & USA & 14 \\
\hline 3 & India & 10 \\
\hline 4 & Australia & 5 \\
\hline 5 & Japan & 4 \\
\hline 6 & South Korea & 3 \\
\hline 7 & United Kingdom & 3 \\
\hline 8 & France & 3 \\
\hline 9 & Singapore & 2 \\
\hline 10 & Portugal & 2 \\
\hline
\end{tabular}

TABLE 5: Top 10 Institutions Contributing to the Research Domain

\begin{tabular}{|c|c|c|}
\hline S/N & Institution & Numbers of Papers \\
\hline 1 & Huaqiao University, Xiamen, China & 7 \\
\hline 2 & Central South University, Changsha, China & 6 \\
\hline 3 & Zhenjiang University, Hangzhou, China & 6 \\
\hline 4 & Tamkang University, Taiwan & 5 \\
\hline 5 & Guangxi University, China & 4 \\
\hline 6 & Guangzhou University, China & 3 \\
\hline 7 & Northeastern State University, Tahlequah, USA & 3 \\
\hline 8 & Muroran Institute of Technology, Muroran, Japan & 2 \\
\hline 9 & Nanjing University of Posts and Telecommunications, \\
& China & 2 \\
\hline 10 & Luoyang Institute of Science and Technology, China & 2 \\
\hline
\end{tabular}

distributed randomly. In large network, the data collection process is delayed to the single MS [28] [49] . [50] introduce the concept of Multiple Mobile Sinks, which will eliminate the delay occurred in data collection by single sink but 
will cost more. To reduce this cost, the concept of sensor cloud was introduced to accumulation and process the data collected from WSNs [51].

\section{1) Data collection in WSNs using Single Static Sink}

This section discusses the data collection models in WSNs which uses only Single Static sink as a point of data collection. In a study by Pan et al., a tree formation algorithm was proposed for ZigBee tree-based WSNs [47]. This algorithm is aimed at supporting both normal and event data collection in WSNs. The result demonstrates that the proposed algorithm performs efficiently. A new data collection and routing mechanism was proposed by Guravaiah and Velusamy [52]. The result demonstrates that the proposed Protocol shows some improvement in comparison to the existing Protocols. Dong et al. proposed a data collection approach coined Reliability and Multipath Counter Routing (RMER) so as to provide reliability and energy efficiency needs [25]. The approach transmits data to a sink by joining multi-hop paths of event monitoring sensor nodes into a one-hop path to combine data. Based on the experimental simulation, the result shows that RMER outperforms other existing approaches compared with. Zhang and Liu proposed a new data collection algorithm, coined Unequal Redundancy Level (URL) to attain good reliability and longer lifetime for WSNs [53]. The result shows that the URL performs effectively. In another study by Xie et al., is an effort to provide an efficient and a more secure data collection in WSNs, the authors proposed a novel data gathering scheme [45]. Based on performance evaluation and security analyses the proposed scheme shows how valid and efficient it is.

In a study by Han et al., the authors proposed a data collection algorithm for cluster-based sensor networks [24]. The result demonstrates that the proposed algorithm can replenish energy for networks effectively. Kulshrestha and Mishra proposed a new transmission scheme for energy balancing [36]. In the process of determining the relay node selection, the proposed scheme takes into deliberation link reliability and the amount of adjacent nodes in the network. The simulation result shows that the proposed scheme performs significantly better in comparison with related schemes. A secured data collection scheme was proposed by Zhang et al. [35]. The proposed scheme improves data privacy through asymmetric semi-homomorphic encryption scheme, and aid in reducing the computational cost by using sparse compressive matrix. The experimental result shows that the proposed scheme attains good result in comparison with the existing schemes. A data volume-based data collection technique that utilized Mobile Data Collector (MDC) was introduced by Akber et al. [54]. In the proposed technique, MDC visit sensor nodes that only have produced data while ignoring the rest of the sensor nodes in the network. The result shows that in comparison with the existing techniques, the proposed technique is more energy efficient. In a study by Cheng et al., a mobile data gathering algorithm with multihop transmission was proposed [26]. The experimental result reveals that the proposed algorithm performs better.

In order to tackle the issue of errors and packet losses during data transmission in WSNs, Sun et al. proposed a data gathering algorithm based on Packet Loss Matching to do just that [44]. Based on simulation result, it reveals that the algorithm can help in alleviating packet losses during data gathering. In an effort to decrease data collection delay and energy consumption of sensor nodes, Kang et al. proposed a scheme for the collection of data from nodes with minimal energy consumption [55]. The result shows that the proposed scheme gives some improvement with regards to data collection delay and energy consumption. To decrease delay and further enhance reliability for data collection in delay and loss-sensitive WSN, Teng et al. proposed a scheme to facilitate data collection. [43]. The idea behind the scheme is to basically extend transmission range so as to facilitate data collection with improved reliability. Based on the results, the proposed scheme improved data collection reliability, reduced data collection time, and also reduced the overall energy consumption. Li et al. proposed a novel data collection scheme to help gather sensed data in an energy-efficient and load-balanced way [33]. The authors compared the proposed scheme with existing schemes used for data collection. Based on the result, the proposed scheme performs better.

In a study by Hasnain et al., the authors proposed a new scheme for WSNs so as to guarantee dependable data communication with effective node battery dissipation [56]. The proposed routing scheme reduces data loss by appointing a group of forwarder nodes that helps in extenuating re-transmissions from network communication. The result demonstrates that the proposed scheme outperforms the existing schemes with regards to energy and packet delivery ratio. Biswas et al. proposed a new data collection algorithm to minimize WSNs lifetime [14]. The evaluation reveals that the proposed algorithm is promising. In a study by Zhang et al., the researchers proposed a new data collection scheme named ring topology based compressive sensing data collection scheme (RTCS) [57]. The experimental result demonstrates the performance of the proposed scheme, which is better than the existing schemes. In another study by Yi et al., an enhanced online fountain coding scheme was proposed [27]. Hence, to reliably sensed data gathering over WSNs, the authors further designed a coding scheme based on the proposed improved online fountain codes. Based on simulation, the result shows that the proposed scheme shows some improvements.

Chen et al. proposed a new data collection scheme for efficient data collection [58]. The proposed scheme is designed to work in industrial WSNs (IWSNs). The simulation result shows that LACD-EDC gives better recovery performance than traditional compression schemes. Tan et al. proposed a scheme to decrease data collection delay and to enhance efficient energy usage of a network [18] . The experimental result demonstrates that the proposed scheme performs better in comparison to traditional data collection schemes. Cai et al. proposed a new data collection scheme for under water 
mobile elements [22]. The scheme takes into consideration mobility direction and velocity. The result shows that the proposed scheme enhanced the efficacy of data collection and also decreases energy intake of nodes. In another study by Caillouet et al., the authors addressed the problem of Aerial Data Collection Problem (ADCP) [37]. The study objectives are to use Unmanned Aerial Vehicles (UAVs) to gather data from mobile wireless sensors and transmit this data to a central base station while decreasing the total deployment cost. The result of the study demonstrates that the approach is effective in minimizing data collection cost. In a recent study by Ullah et al., two routing protocols for underwater WSNs named effective energy and reliable delivery (EERD) and cooperative effective energy and reliable delivery (CoEERD) where proposed [59]. EERD is aimed at minimizing energy consumption while CoEERD enhances network reliability. Based on experimental simulation, the results how that EERD and CoEERD routing protocols have enhanced performance in terms of packet delivery reliability, delay, and energy utilization.

Lesson Learned

\section{2) Data Collection in WSNs using Multiple Static Sink}

This section discusses works on data collection model in WSNs which uses only Multiple Static Sink as a point of data collection. In an early study by Das et al., the authors investigate the issues of energy savings experienced in data collection from multiple sinks in WSNs [60]. Oyman and Ersoy [61] and Vincze et al. [62] gives some recommendations and directions on deployment of multiple sinks in a harmonized way. The aim was to help in minimizing the average communication distance from sensor to the closest sink in a WSN. In a work by Deng et al., the authors conducted an investigation on data collection problem by multiple sinks [63] [64]. The authors further proposed a near-optimal inline algorithm to aid in facilitating the identification of sink location with great approximation ratio.

Lesson Learned

\section{3) Data Collection in WSN using Single Mobile Sink}

This section discusses works on data collection model in WSNs which uses only Single Mobile Sink (MS) as a point of data collection. Wohlers et al. proposed a novel hybrid algorithm for data collection, named TwinRoute [65]. The authors show that the combination of proactive and reactive data collection modes is indeed beneficial. By utilizing both artificial and real-world network topologies with sink traces in their experiment, the result shows that the proposed algorithm outperforms existing approaches for data collection. The algorithm helps in balancing the tradeoffs between energy consumption and timely-delivery of sensor data. In another study by Kusy et al., an algorithm based on information potentials was proposed to aid in data delivery to MS in WSNs [66]. The authors further introduce mobility graph to tackle the problem of iterative computation that leads to packet loss and packet delivery delays. The results demonstrate that the proposed algorithm can sustain uninterrupted data streams. A routing scheme was proposed by Lee et al. [67] to explore mobile sinks behavior within a network. The authors' objective is to reduce energy consumption and congestion in a network. The result shows that the scheme can decrease the amount of transmissions required for data delivery to MS. A study by Li et al., the authors proposed a novel approach for data collection in WSNs [68]. Based on the authors' analysis and conclusion, the proposed approach is scalable, efficient, and delivers continuous data delivery during a user movement. In an effort to decide the best position for a single mobile sink in a WSNs, Wang et al. proposed a data collection algorithm named Global Best Path (GBP). The algorithm used global sensors' information to produce the best scheme to help in gathering data from a specific node of interest [48]. The results demonstrate that the proposed algorithm performs better than algorithms such as LEACH, GAF, and so on. In a given wireless sensor network with rendezvous points (RPs) in which an MS node only visits these RPs, and all sensor nodes (nodes that are not RPs) have to forward their sensed data to the nearest RP through multi-hopping, one of the issues that arises is the computation of tour that visits all the RPs with a given delay bound. Looking at this problem, Salarian et al. proposed a weighted rendezvous planning (WRP) heuristic to tackle the problem [15]. The heuristic assigned a weight to each sensor node that corresponds to the node's hop distance from the tour with the quantity of data packets that the node's forwards to the nearest RP. The result shows that the proposed heuristic is useful in decreasing energy consumption and improve data retrieval of a mobile sink within a given deadline. In another study by Bagheri and Mehdi, the authors also utilized RPs to called data from sensor nodes [49]. Using the RP allows the MS to collect a huge volume of data with minimal energy cost and less time. The result of the study confirms the effectiveness of utilizing RPs from energy-saving and timely delivery perspective of sensed data in comparison to other existing methods.

Cheng and Yu proposed a method that helps in decreasing the length of the traveling path for a MS to decrease the delay time during data gathering [69]. The experimental result shows that the proposed method gives a good outcome with respect to computational effort and the length of the MS traveling path. In an effort to resolve the problem of data gathering in Rechargeable Sensor Networks (RSNs) with a MS, Zhang et al. proposed an approach named Distributed Data Gathering Approach (DDGA) [40]. The approach is used by general sensors to attain the ideal data collection scheme. Based on simulations conducted, the authors demonstrate the approach to be very efficient. Due to the instability of multi-hop transmission in WSNs, Du et al. proposed a data collection mechanism that utilizes mobile-based stations [70]. The result shows that the mechanism reduces energy consumption, and reduce transmission delay time. 
Furthermore, a data collection strategy was proposed by Zhu et al. [31]. The proposed strategy is aimed to decrease routing energy consumption by shorting the total length of routing paths. The results show that, in comparison with the existing works, the proposed strategy outperforms them. Yang et al. focused on low-delay and high-throughput data collection in WSNs with MS [41]. The authors proposed a novel routing metric named Contact-Aware ETX (CAETX) to aid in calculating and estimating packet transmission delay. Based on their experiment, the authors conclude that the proposed metric outperforms current approaches. In an effort to tackle the problem of WSNs splits that occur because of the random deployment of sensor nodes, Shrirame and Mini design a travel path for MS so as to decrease tour length and energy consumption of sensor nodes [71]. The result reveals that the method outperforms existing algorithms. In another work by Tashtarian et al., an approach was proposed to determine the ideal trajectory of a given MS without considering any RPs [72]. The proposed approach was compared with existing state-of-the-art approach and a scenario that utilizes RPs for routing. In the quest to extend the lifetime of WSNs, Yang et al. proposed an algorithm named Heuristic algorithm [73]. The results demonstrate that the algorithm outperforms existing methods.

Kaswan et al. proposed two algorithms for path routing for MS [30]. The first algorithm used RPs to design better and efficient trajectory for MS while the second takes delay bound path formation of a MS into consideration. The authors further proposed a scheduling technique for MS to aid in effective data collection. The simulations reveal that the proposed algorithm performs better in comparison to the existing algorithms. Cheng et al. also proposed two algorithms, named Trail-based Algorithm with Virtual Guide Line (TAG) and enhanced Trail-based Algorithm with Virtual Guide Line (eTAG) [74]. The aim of these algorithms is to swiftly locate the continually moving MSs by the sensor nodes and send packets via small number of forwarding hop counts. The result demonstrates that the proposed algorithms can assure the identification of constant moving MSs and also reduce the forward hop counts. In a study by Huang and Savkin, the authors proposed a protocol composed of an energyaware unequal clustering algorithm and an energy-aware routing algorithm [16]. The protocol is aimed at balancing energy consumption while transmitting data packet across a network. The results reveal that the proposed protocol is effective.

Rashed and Soyturk study the Unmanned Aerial Vehicles (UAVs) mobility patterns that move through different paths [32]. The authors proposed a novel metric to allow tradeoff between the maximization of nodes coverage and minimization of the operation time when selecting the right mobility design. The result shows that the study findings are useful. In another study by Cao et al., an approach for data gaining in WSNs was proposed [34]. In comparison with the existing methods, the proposed approach performs better. Wen et al. proposed an efficient data collection mechanism [75]. The mechanism is aimed at selecting a group of sensors to mimic the role of RPs that could be visited by MS. The result shows that the proposed mechanism outperforms existing methods. In another study by Kim et al., a regional density-aware data collection (RDDC) method was proposed [76]. The method used UAVs in large-scale wireless sensor networks. The method is aimed at fast-tracking data collection by amending the minimum contention window value of a sensor node. Based on the works experiment, the result show that RDDC performs relatively better in comparison with the existing methods.

Cheng et al. proposed a mobile data collection algorithm with multi-hop transmission [26]. The algorithm helps in reducing the amount of visiting points by visiting the merging area of sensors' communication ranges. The results reveal that the proposed algorithm is useful and performs better. In order to alleviate the impact of dissimilar distribution categories of events on data collection, Zhu et al. proposed a virtual grid-based real-time data collection algorithm (VGDCAC) [77]. This algorithm is specifically for applications with centrally distributed events. The aim of the algorithm is to achievement a dependable data gathering for industrial WSNs (IWSNs). The result shows that VGDCA-C reduces transmission delay and improve network lifetime. He et al. proposed a hybrid routing method to decrease network energy consumption and a data collection scheme [21]. The result of the study shows that the proposed scheme and method have performed very well in terms of enhancing packet delivery and reducing energy consumption in a heterogeneous WSNs. In an effort to tackle the issue of unbalanced data transference in communication channel and improve network lifetime, Krishnan et al. proposed an approach to address those issues [28]. The result demonstrated that the proposed approach is beneficial. Zhu et al. proposed a data gathering scheme with MS [46]. The result demonstrates that the proposed scheme performs better in comparison with the existing scheme.

$\mathrm{Li}$ et al. proposed a heuristic algorithm to effectively estimate the optimal scheduling solution in polynomial time. The result shows that the proposed algorithm performs better with high data reception rates in different constraints [42]. A strategy for data collection named a reducing delay and maximizing lifetime (RDML) was proposed by Wang et al. [17]. The result shows that RDML can decrease the delay of data collection in comparison with existing strategies. Liu et al. proposed a far-relay approach to tackle the issue of joint data collection in rechargeable wireless sensor networks (RWSNs) [1]. Based on simulation experiments, the proposed approach performs better. In a study by Huang et al., the authors proposed a data collection strategy that is aimed at resolving the problem of data collection in a delaytolerant WSN with MS [29]. The result demonstrates that the proposed strategy can enhance network lifetime.

Table 6 gives a summary of all the studies that utilized single MSs (30 studies). Parameters such as the routing schemes they utilized, mobile elements, sink type, performance met- 
rics, and networks sizes were highlighted with respect to each study. The analysis shows that 21 studies utilized multi-hop for their routing transmission, and 9 studies utilized singlegop transmission.

Lesson Learned

\section{4) Data Collection in WSN using Multiple Mobile Sink}

Nowadays, communication devices produce a lot of data that have to be handled and processed on time. Hence, the concept of MS was introduced to deal with data collection from WSNs. In most cases, the data is transmitted to the sink by utilizing the sensor node near the sink which will create burden on the node and drain the node's energy. This will create a hotspot issue. To tackle the hotspot issue, the MS was introduced to gather the data from the network and forward the data to the base station. In large network, data collection using single sink takes time which is critical for some delay-sensitive applications. The author in [50] introduces the concept of Multiple Mobile Sink (MMS) to reduce the delay in data collection in some delay-sensitive applications of WSNs. In the last few years, there are few papers that explore the utilization of MMS for data collection in WSNs. We have identified seven papers that addressed this issue and shows the importance of adopting MMS in terms of minimization of latency, energy consumption savings, fast data delivery, and much more. Subsequently, studies that utilized MMS will be presented in this section.

Shi et al. study the energy management issue by utilizing MMS [50]. The authors proposed an algorithm named energy management algorithm in a WSNs with MMS (EMMS). This algorithm helps in balancing the workload among the MS, and also among sensor nodes. The result demonstrates that the proposed algorithm is very promising. Bell and Asir conduct a performance study to quantify network delay with MMS [78]. A Mobility Assisted Data Collection (MADC) model was utilized to separate mobile data. Various Parameters like throughput, network lifetime, and delay were used to quantify network performance with MMS. In another study by Xie et al., the authors proposed an energy-efficient routing mechanism with deliberate mobility to WSNs with obstacles [79]. The result shows that the proposed mechanism is promising.

With the support of MMS, Zhong and Ruan proposed an energy-efficient clustering algorithm for WSNs [80]. The result demonstrates that the proposed algorithm performance improved when there are around three MS in the network. Usman et al. proposed a secure data collection scheme using MS in wireless multimedia sensor networks (WMSNs) [81]. The result demonstrates that the proposed scheme gives better performance. Faheem and Gungor proposed a new data collection protocol for WSNs smart grid applications, named multi-mobile sinks-based QoS-aware data gathering aware protocol (MQRP) [39]. The protocol has been proposed so as to empower smart grid 4.0. Based on simulation study, the result demonstrates that the proposed protocol enhanced
Quality of Service (QoS) compare to the existing protocols. In a recent study by Kumar and Ashok, the authors proposed a novel Location-Aware Routing for controlled MS (LARCMS) [82]. The routing protocol is proposed to help in reducing delay, improving network lifetime, handling MS location updates, and proving even energy consumption. The result demonstrates that the proposed protocol performance is promising.

\section{5) Essentially and Challenges of Data Collection in WSNs}

WSNs consist of sensor nodes, that are tiny in size. The main aim of these nodes is to collect data from the environment where these nodes are deployed. The collected data are crucial for decision making in different organization. If this data is not collected on times, there may be a significant loss to the organization. Therefore on-time data collecton is very essential. Several internal and external challenges can affect the data collection process. For example, if the nodes are deployed in a harsh environment, whereas the data is an important fact and figure for decision making. In the case of WSNs, the information is a critical factor for the decision of the whole system where sensor nodes are deployed as the deployed node collect data from the target event. When the data are collected on time, the decision taken on the collected data will be appropriate. If the data collection process is delayed, the decision will be taken wrongly, and due to this wrong decision, the whole system will be collapsed. So on time data collection is very important. Let suppose we will take an example of precision agriculture. In WSNs, the Unmanned Aerial Vehicles (UAVs) is used to collect the data from the agriculture field. These data are used to excerpt information on biomass levels which further helps in accomplishing useful insights on prospects of crop diseases, pest invasion, nutrient insufficiency and several other aspects affecting productivity. [83] .Similarly, the data collected from the sensor nodes deployed in healthcare and military are needed to be confidential. The sensor nodes deployed in these sector need proper security mechanism to keep the data secure from unauthorized parties. [84]

\section{B. DATA COLLECTION IN SENSOR CLOUD}

This section discusses the data collection models in sensor cloud. Bhunia et al. proposed a data collection scheme in sensor cloud infrastructure [51]. The proposed scheme makes use of fuzzy logic to guarantee efficient data collection and reporting. The work shows that the proposed scheme is useful. Due to the challenges faced when transmitting data from WSNs to the cloud, Chatterjee et al. introduced the use of a general pairwise choice framework over virtual sensor networks (VSNs) to deal with the challenge [85]. The framework achieved significant reduction in energy consumption. Songar and Uthra proposed a new energy-efficient routing protocol for WSN so as to save nodes' energy and also integrate WSN with cloud [86]. In a study by Wang et al., a fog structure was proposed that comprised of MMS [47]. The MSs act as fog nodes so as to close the gap between WSNs 
TABLE 6: Summary of studies that uses Single Mobile Sink based on defined Parameters

\begin{tabular}{|c|c|c|c|c|c|c|}
\hline Schemes & Contribution & $\begin{array}{l}\text { Routing } \\
\text { Scheme }\end{array}$ & $\begin{array}{l}\text { Mobile el- } \\
\text { ements }\end{array}$ & $\begin{array}{l}\text { Sink } \\
\text { Type }\end{array}$ & $\begin{array}{l}\text { Performance } \\
\text { Metrics }\end{array}$ & $\begin{array}{l}\text { Network } \\
\text { Size }\end{array}$ \\
\hline $\begin{array}{l}\text { Huang et } \\
\text { al. [29] }\end{array}$ & $\begin{array}{l}\text { The authors proposed a data collec- } \\
\text { tion strategy that is aimed at resolv- } \\
\text { ing the problem of data collection } \\
\text { in a delay-tolerant wireless sensor } \\
\text { network with mobile sink }\end{array}$ & $\begin{array}{l}\text { Multi- } \\
\text { hop }\end{array}$ & One & $\begin{array}{l}\text { Mobile } \\
\text { sinks }\end{array}$ & Energy efficiency & Nil \\
\hline $\begin{array}{l}\text { Liu et al. } \\
\text { [1] }\end{array}$ & $\begin{array}{l}\text { The authors proposed a far-relay } \\
\text { approach to tackle the problem of } \\
\text { joint data collection and energy har- } \\
\text { vesting (JoDGE) in rechargeable } \\
\text { wireless sensor networks (RWSNs) }\end{array}$ & $\begin{array}{l}\text { Multi- } \\
\text { hop }\end{array}$ & One & $\begin{array}{l}\text { Mobile } \\
\text { sinks }\end{array}$ & Energy efficiency & $100 \mathrm{~m} * 50 \mathrm{~m}$ \\
\hline $\begin{array}{l}\text { Wang et } \\
\text { al. [17] }\end{array}$ & $\begin{array}{l}\text { The authors proposed a strategy } \\
\text { for data collection named a reduc- } \\
\text { ing delay and maximizing lifetime } \\
\text { (RDML) }\end{array}$ & $\begin{array}{l}\text { Multi- } \\
\text { hop }\end{array}$ & One & $\begin{array}{l}\text { Mobile } \\
\text { sinks }\end{array}$ & $\begin{array}{l}\text { Energy } \\
\text { consumption, } \\
\text { Energy } \\
\text { utilization ratio, } \\
\text { Network lifetime }\end{array}$ & Nil \\
\hline $\begin{array}{l}\text { Li et al. } \\
\text { [42] }\end{array}$ & $\begin{array}{l}\text { The authors proposed a heuristic } \\
\text { algorithm to effectively estimate } \\
\text { the optimal scheduling solution in } \\
\text { polynomial time }\end{array}$ & $\begin{array}{l}\text { Single- } \\
\text { hop }\end{array}$ & One & $\begin{array}{l}\text { Mobile } \\
\text { sinks }\end{array}$ & $\begin{array}{l}\text { Energy and effi- } \\
\text { ciency }\end{array}$ & Nil \\
\hline $\begin{array}{l}\text { Zhu et al. } \\
{[46]}\end{array}$ & $\begin{array}{l}\text { The authors proposed a high- avail- } \\
\text { able and location predictive data } \\
\text { gathering scheme with mobile sink }\end{array}$ & $\begin{array}{l}\text { Multi- } \\
\text { hop }\end{array}$ & One & $\begin{array}{l}\text { Mobile } \\
\text { sinks }\end{array}$ & $\begin{array}{l}\text { Energy consump- } \\
\text { tion and Network } \\
\text { lifetime }\end{array}$ & Nil \\
\hline $\begin{array}{l}\text { Krishnan } \\
\text { et al. } \\
{[28]}\end{array}$ & $\begin{array}{l}\text { The authors proposed an approach } \\
\text { to address the issue of unbalanced } \\
\text { data transference in the communi- } \\
\text { cation channel }\end{array}$ & $\begin{array}{l}\text { Single- } \\
\text { hop }\end{array}$ & One & $\begin{array}{l}\text { Mobile } \\
\text { sinks }\end{array}$ & Network lifetime & $200 * 200 \mathrm{~m}^{2}$ \\
\hline $\begin{array}{l}\text { He et al. } \\
{[21]}\end{array}$ & $\begin{array}{l}\text { The authors proposed a hybrid rout- } \\
\text { ing method to reduce network en- } \\
\text { ergy consumption and a data collec- } \\
\text { tion scheme }\end{array}$ & $\begin{array}{l}\text { Single- } \\
\text { hop }\end{array}$ & One & $\begin{array}{l}\text { Mobile } \\
\text { sinks }\end{array}$ & $\begin{array}{l}\text { Energy consump- } \\
\text { tion and Packet } \\
\text { delivery ratio }\end{array}$ & $\begin{array}{l}800 \mathrm{~m} \\
* 800 \mathrm{~m}\end{array}$ \\
\hline $\begin{array}{l}\text { Zhu et al. } \\
\text { [77] }\end{array}$ & $\begin{array}{l}\text { The authors proposed a virtual grid- } \\
\text { based real-time data collection al- } \\
\text { gorithm (VGDCAC) }\end{array}$ & $\begin{array}{l}\text { Multi- } \\
\text { hop }\end{array}$ & One & $\begin{array}{l}\text { Mobile } \\
\text { sinks }\end{array}$ & $\begin{array}{l}\text { Network lifetime, } \\
\text { Average residual } \\
\text { energy, } \\
\text { of riance } \\
\text { energy, residual } \\
\text { Average number } \\
\text { of transmission } \\
\text { hops }\end{array}$ & $200 \mathrm{~m} * 200 \mathrm{~m}$ \\
\hline $\begin{array}{l}\text { Cheng et } \\
\text { al. [26] }\end{array}$ & $\begin{array}{l}\text { The authors proposed a mobile } \\
\text { data collection algorithm named } \\
\text { Bounded Relay Combine-TSP- } \\
\text { Reduce (BRCTR) }\end{array}$ & $\begin{array}{l}\text { Multi- } \\
\text { hop }\end{array}$ & One & $\begin{array}{l}\text { Mobile } \\
\text { sinks }\end{array}$ & $\begin{array}{l}\text { Length of } \\
\text { traveling path, } \\
\text { Delay time, } \\
\text { Network lifetime, } \\
\text { and buffer size }\end{array}$ & $500 * 500 \mathrm{~m}^{2}$ \\
\hline $\begin{array}{l}\text { Kim et } \\
\text { al. [76] }\end{array}$ & $\begin{array}{l}\text { The authors proposed a regional } \\
\text { density-aware data collection } \\
\text { (RDDC) method }\end{array}$ & $\begin{array}{l}\text { Single- } \\
\text { hop }\end{array}$ & One & $\begin{array}{l}\text { Mobile } \\
\text { sinks }\end{array}$ & $\begin{array}{l}\text { Delay and Aggre- } \\
\text { gate throughput }\end{array}$ & $1000 * 1000 \mathrm{~m}^{2}$ \\
\hline $\begin{array}{l}\text { Wen et } \\
\text { al. [75] }\end{array}$ & $\begin{array}{l}\text { The authors proposed an efficient } \\
\text { data collection mechanism }\end{array}$ & $\begin{array}{l}\text { Multi- } \\
\text { hop }\end{array}$ & One & $\begin{array}{l}\text { Mobile } \\
\text { sinks }\end{array}$ & $\begin{array}{l}\text { Energy consump- } \\
\text { tion and Network } \\
\text { lifetime }\end{array}$ & $200 \mathrm{~m} * 200 \mathrm{~m}$ \\
\hline
\end{tabular}




\begin{tabular}{|c|c|c|c|c|c|c|}
\hline \multicolumn{7}{|c|}{ Continue Table 6} \\
\hline Schemes & Contribution & $\begin{array}{l}\text { Routing } \\
\text { Scheme }\end{array}$ & $\begin{array}{l}\text { Mobile el- } \\
\text { ements }\end{array}$ & $\begin{array}{l}\text { Sink } \\
\text { Type }\end{array}$ & $\begin{array}{l}\text { Performance } \\
\text { Metrics }\end{array}$ & $\begin{array}{l}\text { Network } \\
\text { Size }\end{array}$ \\
\hline $\begin{array}{l}\text { Cao et al. } \\
{[34]}\end{array}$ & $\begin{array}{l}\text { The authors proposed a Cloud as- } \\
\text { sisted approach for deriving UAVs } \\
\text { optimal flying and data gaining se- } \\
\text { quence of wireless sensor networks }\end{array}$ & $\begin{array}{l}\text { Multi- } \\
\text { hop }\end{array}$ & One & $\begin{array}{l}\text { Mobile } \\
\text { sinks }\end{array}$ & $\begin{array}{l}\text { Time, Distance, } \\
\text { and } \quad \text { Energy } \\
\text { consumption }\end{array}$ & $1000 * 1000 \mathrm{~m}^{2}$ \\
\hline $\begin{array}{l}\text { Rashed } \\
\text { and } \\
\text { Soyturk } \\
{[32]}\end{array}$ & $\begin{array}{l}\text { The authors proposed a new met- } \\
\text { ric to allow a trade off between } \\
\text { the maximizing the nodes coverage } \\
\text { and minimizing the operation time } \\
\text { when selecting the right mobility } \\
\text { pattern }\end{array}$ & $\begin{array}{l}\text { Single- } \\
\text { hop }\end{array}$ & One & $\begin{array}{l}\text { Mobile } \\
\text { sinks }\end{array}$ & $\begin{array}{l}\text { Coverage, Time } \\
\text { efficiency and } \\
\text { utilization, } \\
\text { and Coverage } \\
\text { efficiency }\end{array}$ & $2000 * 2000 \mathrm{~m}^{2}$ \\
\hline $\begin{array}{l}\text { Huang } \\
\text { and } \\
\text { Savkin } \\
{[16]}\end{array}$ & $\begin{array}{l}\text { The authors proposed a protocol } \\
\text { that composed of an energy-aware } \\
\text { unequal clustering algorithm and an } \\
\text { energy-aware routing algorithm }\end{array}$ & $\begin{array}{l}\text { Multi- } \\
\text { hop }\end{array}$ & One & $\begin{array}{l}\text { Mobile } \\
\text { sinks }\end{array}$ & $\begin{array}{l}\text { Network } \\
\text { lifetime and } \\
\text { Average energy } \\
\text { consumption }\end{array}$ & $100 * 100 \mathrm{~m}^{2}$ \\
\hline $\begin{array}{l}\text { Cheng et } \\
\text { al. [74] }\end{array}$ & $\begin{array}{l}\text { The authors proposed two algo- } \\
\text { rithms, named Trail-based Algo- } \\
\text { rithm with Virtual Guide Line } \\
\text { (TAG) and enhanced Trail-based } \\
\text { Algorithm with Virtual Guide Line } \\
\text { (eTAG) }\end{array}$ & $\begin{array}{l}\text { Multi- } \\
\text { hop }\end{array}$ & One & $\begin{array}{l}\text { Mobile } \\
\text { sinks }\end{array}$ & $\begin{array}{l}\text { Data delivery ra- } \\
\text { tio and Network } \\
\text { traffic }\end{array}$ & $500 * 500 \mathrm{~m}^{2}$ \\
\hline $\begin{array}{l}\text { Kaswan } \\
\text { et al. } \\
{[30]}\end{array}$ & $\begin{array}{l}\text { The authors proposed two algo- } \\
\text { rithms for path routing for mobile } \\
\text { sink }\end{array}$ & $\begin{array}{l}\text { Multi- } \\
\text { hop }\end{array}$ & One & $\begin{array}{l}\text { Mobile } \\
\text { sinks }\end{array}$ & $\begin{array}{l}\text { Energy consump- } \\
\text { tion and Network } \\
\text { lifetime }\end{array}$ & $220 * 220 \mathrm{~m}^{2}$ \\
\hline $\begin{array}{l}\text { Yang et } \\
\text { al. [73] }\end{array}$ & $\begin{array}{l}\text { proposed an algorithm named } \\
\text { Heuristic algorithm }\end{array}$ & Nil & One & $\begin{array}{l}\text { Mobile } \\
\text { sinks }\end{array}$ & Nil & Nil \\
\hline $\begin{array}{l}\text { Tashtarian } \\
\text { et al. } \\
{[72]}\end{array}$ & $\begin{array}{l}\text { The authors proposed to determine } \\
\text { the ideal trajectory of a given mo- } \\
\text { bile sink without considering any } \\
\text { RPs }\end{array}$ & $\begin{array}{l}\text { Multi- } \\
\text { hop }\end{array}$ & One & $\begin{array}{l}\text { Mobile } \\
\text { sinks }\end{array}$ & $\begin{array}{l}\text { Data } \\
\text { paths, Transmission } \\
\text { rates,and } \\
\text { Efficiency }\end{array}$ & $100 * 200 \mathrm{~m}^{2}$ \\
\hline $\begin{array}{l}\text { Shrirame } \\
\text { and Mini } \\
{[71]}\end{array}$ & $\begin{array}{l}\text { The authors design a travel path for } \\
\text { the mobile sink so as to minimize } \\
\text { tour length and energy consumption } \\
\text { of sensor nodes }\end{array}$ & $\begin{array}{l}\text { Single- } \\
\text { hop }\end{array}$ & One & $\begin{array}{l}\text { Mobile } \\
\text { sinks }\end{array}$ & $\begin{array}{l}\text { Tour length and } \\
\text { Energy consump- } \\
\text { tion }\end{array}$ & $100 * 100 \mathrm{~m}^{2}$ \\
\hline $\begin{array}{l}\text { Yang et } \\
\text { al. [41] }\end{array}$ & $\begin{array}{l}\text { The authors proposed a novel rout- } \\
\text { ing metric named Contact- Aware } \\
\text { ETX (CA-ETX) to aid in calculat- } \\
\text { ing and estimating packet transmis- } \\
\text { sion delay }\end{array}$ & $\begin{array}{l}\text { Multi- } \\
\text { hop }\end{array}$ & One & $\begin{array}{l}\text { Mobile } \\
\text { sinks }\end{array}$ & $\begin{array}{l}\text { Packet } \\
\text { transmission de- } \\
\text { lay,Communication } \\
\text { overhead, and } \\
\text { Reliability }\end{array}$ & $1000 * 1000 \mathrm{~m}^{2}$ \\
\hline $\begin{array}{l}\text { Zhu et al. } \\
\text { [31] }\end{array}$ & $\begin{array}{l}\text { The authors proposed a greedy } \\
\text { scanning data collection strategy } \\
\text { (GSDCS) }\end{array}$ & $\begin{array}{l}\text { Multi- } \\
\text { hop }\end{array}$ & One & $\begin{array}{l}\text { Mobile } \\
\text { sinks }\end{array}$ & $\begin{array}{l}\text { Network lifetime } \\
\text { and Energy con- } \\
\text { sumption }\end{array}$ & $200 \mathrm{~m}$ \\
\hline $\begin{array}{l}\text { Du et al. } \\
{[70]}\end{array}$ & $\begin{array}{l}\text { The authors proposed a data } \\
\text { collection mechanism that uses } \\
\text { mobile-based stations. The } \\
\text { mechanism composed of three } \\
\text { proposed components, which } \\
\text { are Time High-Overflow-based } \\
\text { Dominating algorithm (THD), } \\
\text { Temporary Caching Mechanism } \\
\text { (TCM), and lastly Dominating- } \\
\text { based Minimum Weighted Sum } \\
\text { (DMWS) protocol. }\end{array}$ & $\begin{array}{l}\text { Single- } \\
\text { hop }\end{array}$ & One & $\begin{array}{l}\text { Mobile } \\
\text { sinks }\end{array}$ & $\begin{array}{l}\text { Time } \\
\text { delay,Network } \\
\text { lifetime,and } \\
\text { Energy } \\
\text { consumption }\end{array}$ & Nil \\
\hline & & & & & & \\
\hline
\end{tabular}




\begin{tabular}{|c|c|c|c|c|c|c|}
\hline \multicolumn{7}{|c|}{ Continue Table 6} \\
\hline Schemes & Contribution & $\begin{array}{l}\text { Routing } \\
\text { Scheme }\end{array}$ & $\begin{array}{l}\text { Mobile el- } \\
\text { ements }\end{array}$ & $\begin{array}{l}\text { Sink } \\
\text { Type }\end{array}$ & $\begin{array}{l}\text { Performance } \\
\text { Metrics }\end{array}$ & $\begin{array}{l}\text { Network } \\
\text { Size }\end{array}$ \\
\hline $\begin{array}{l}\text { Zhang et } \\
\text { al. [40] }\end{array}$ & $\begin{array}{l}\text { The authors proposed an approach } \\
\text { named Distributed Data Gathering } \\
\text { Approach (DDGA) }\end{array}$ & $\begin{array}{l}\text { Multi- } \\
\text { hop }\end{array}$ & One & $\begin{array}{l}\text { Mobile } \\
\text { sinks }\end{array}$ & $\begin{array}{l}\text { Energy consump- } \\
\text { tion }\end{array}$ & $60 * 60 \mathrm{~m}^{2}$ \\
\hline $\begin{array}{l}\text { Cheng } \\
\text { and Yu } \\
{[69]}\end{array}$ & $\begin{array}{l}\text { The authors proposed a method that } \\
\text { helps in shortening the length of the } \\
\text { traveling path for a mobile sink to } \\
\text { reduce the delay time during data } \\
\text { gathering. }\end{array}$ & $\begin{array}{l}\text { Single- } \\
\text { hop }\end{array}$ & One & $\begin{array}{l}\text { Mobile } \\
\text { sinks }\end{array}$ & $\begin{array}{l}\text { Computational } \\
\text { effort and length } \\
\text { of the traveling } \\
\text { path }\end{array}$ & $500 * 500 \mathrm{~m}^{2}$ \\
\hline $\begin{array}{l}\text { Bagheri } \\
\text { and } \\
\text { Mehdi } \\
{[49]}\end{array}$ & $\begin{array}{l}\text { The authors utilized RPs to called } \\
\text { data from sensor nodes }\end{array}$ & $\begin{array}{l}\text { Multi- } \\
\text { hop }\end{array}$ & One & $\begin{array}{l}\text { Mobile } \\
\text { sinks }\end{array}$ & $\begin{array}{l}\text { Energy } \\
\text { consumption, } \\
\text { Data delivery } \\
\text { delay, and Data } \\
\text { delivery ratio }\end{array}$ & $100 * 100 \mathrm{~m}^{2}$ \\
\hline $\begin{array}{l}\text { Salarian } \\
\text { et al. } \\
{[15]}\end{array}$ & $\begin{array}{l}\text { The authors proposed a weighted } \\
\text { rendezvous planning (WRP) heuris- } \\
\text { tic }\end{array}$ & $\begin{array}{l}\text { Multi- } \\
\text { hop }\end{array}$ & One & $\begin{array}{l}\text { Mobile } \\
\text { sinks }\end{array}$ & $\begin{array}{l}\text { Energy consump- } \\
\text { tion and Network } \\
\text { lifetime }\end{array}$ & $200 \mathrm{~m} * 200 \mathrm{~m}$ \\
\hline $\begin{array}{l}\text { Wang et } \\
\text { al. [48] }\end{array}$ & $\begin{array}{l}\text { The authors proposed a data gath- } \\
\text { ering algorithm named Global Best } \\
\text { Path (GBP) }\end{array}$ & $\begin{array}{l}\text { Multi- } \\
\text { hop }\end{array}$ & One & $\begin{array}{l}\text { Mobile } \\
\text { sinks }\end{array}$ & Network lifetime & $100 \mathrm{~m}$ \\
\hline $\begin{array}{l}\text { Li et al. } \\
\text { [68] }\end{array}$ & $\begin{array}{l}\text { The authors proposed a novel ap- } \\
\text { proach for data collection in wire- } \\
\text { less sensor networks }\end{array}$ & $\begin{array}{l}\text { Multi- } \\
\text { hop }\end{array}$ & One & $\begin{array}{l}\text { Mobile } \\
\text { sinks }\end{array}$ & $\begin{array}{l}\text { Efficiency and } \\
\text { Scalability }\end{array}$ & Nil \\
\hline $\begin{array}{l}\text { Lee et al. } \\
\text { [67] }\end{array}$ & $\begin{array}{l}\text { The authors proposed a routing } \\
\text { scheme to explore mobile sinks be- } \\
\text { havior within a network }\end{array}$ & $\begin{array}{l}\text { Single- } \\
\text { hop }\end{array}$ & One & $\begin{array}{l}\text { Mobile } \\
\text { sinks }\end{array}$ & $\begin{array}{ll}\text { Packet delivery } \\
\text { ratio }\end{array}$ & $830 * 790 \mathrm{~m}^{2}$ \\
\hline $\begin{array}{l}\text { Kusy et } \\
\text { al. [66] }\end{array}$ & $\begin{array}{l}\text { The authors proposed an algorithm } \\
\text { based on information potentials to } \\
\text { aid in data delivery to mobile sinks } \\
\text { in wireless sensor networks }\end{array}$ & $\begin{array}{l}\text { Multi- } \\
\text { hop }\end{array}$ & One & $\begin{array}{l}\text { Mobile } \\
\text { sinks }\end{array}$ & $\begin{array}{l}\text { Prediction accu- } \\
\text { racy and Reliabil- } \\
\text { ity }\end{array}$ & $9000 \mathrm{~m}^{2}$ \\
\hline $\begin{array}{l}\text { Wohlers } \\
\text { et al. } \\
\text { [65] }\end{array}$ & $\begin{array}{l}\text { The authors proposed a novel hy- } \\
\text { brid algorithm for data collection, } \\
\text { named Twin Route }\end{array}$ & $\begin{array}{l}\text { Multi- } \\
\text { hop }\end{array}$ & One & $\begin{array}{l}\text { Mobile } \\
\text { sinks }\end{array}$ & $\begin{array}{l}\text { Time to delivery, } \\
\text { Energy consump- } \\
\text { tion }\end{array}$ & $1000 * 1000 \mathrm{~m}^{2}$ \\
\hline
\end{tabular}

and cloud. The method was compared with various existing traditional methods. The experimental result demonstrates that the proposed method has outperformed the traditional methods compared with. With the issue of data upload to cloud in sensor cloud, $\mathrm{Li}$ et al. proposed the use of Multiple Mobile Sinks to aid in data upload from WSNs to cloud [87]. The authors design an algorithm for the scheduling of Multiple Mobile Sinks. Based on simulation, the result shows that the proposed algorithm can upload data from WSNs to cloud in limited time and with minimum energy consumption.

In a study by Capponi et al., a novel framework for data collection was proposed [88]. The proposed framework is set to reduce the total cost of sensing and reporting by approximating performance of operation conducted in distributed manner. The simulation result demonstrates that the proposed approach is very effective. Wang et al. proposed the use of MMS to aid with data collection in sensor cloud integration [89]. Hence, to further reduce data delivery latency instigated primarily by arbitrary task distribution, the authors proposed a data collection algorithm with MMS. Based on simulations, the results demonstrate how effective the proposed algorithm is. Wang et al. proposed a fog structure that is comprised of MMS [13]. The MSs act primarily as fog nodes so as to close the gap between WSNs and the cloud. The method was designed to improve throughput and also reduce transmission latency. A comparative study with existing solutions shows that the proposed method outperforms existing solutions. In another study by Liang et al., proposed a distributed intelligent algorithm to address the issue of transmission delay and high energy consumption of fog nodes [2]. The result reveals that the proposed algorithm can attain minimal delay and decrease energy consumption in comparison to existing works. To advance the recovery of originally lost data, Chen et al. proposed a compressive data collection scheme [90] . The simulation result demonstrates the effectiveness of the scheme. A data collection approach named a comprehensive trustworthy data collection approach (CTDC) for sensor 
cloud systems was proposed by Wang et al. [12] . The result of a simulation conducted shows that the proposed approach improved performance in data collection. In Table 7, the merits and weaknesses of each analyzed proposal in this section are outlined.

Lesson Learned

\section{1) Essentially and Challenges of Data Collection in Sensor} Cloud

[91], [3], [12]

\section{DATA COLLECTION IN IOT}

In the last few years, few papers have been published specific to data collection in IoT. In this section, we have identified 11 papers on IoT data collection. As shown in Figure 4, research on data collection in IoT is gaining traction since 2017. Hence, in this section, these papers are discussed in detail.

In a study by Cecchinel et al., the authors define a software architecture so as to support the collection of sensor based data in IoT environment [92]. The framework supports Big Data research with the gathering of huge datasets acquired from physical sensors. In another study by Shi et al., a system named Opportunistic Networking Connectivity Service (OppNet) was proposed [93]. The result shows that OppNet performs very well in terms of delay and hops count. To provide data-centric universal data gathering of hypermedia Big Data in IoT, $\mathrm{Xu}$ et al. proposed a distributed algorithm named EQRoute to do just that [23]. Based on extensive analysis and simulations, the result shows that the proposed algorithm made a significant improvement. Zhu et al. developed a twophase scheme to help in management of data uploading for mobile data collectors [94]. The proposed approach will aid in enhancing the effectiveness of data collection. The result demonstrates that the proposed approach yields substantial improvements in comparison to existing solutions. Fan et al. proposed an algorithm to balance workload in fog network so as to decrease data flows latency during communications and processing with IoT devices to suitable Base Stations [95] . The proposed scheme is named LoAd Balancing (LAB) scheme. Based on the simulation, LAB performs better than schemes compared with in terms of load balancing and latency reduction. Rahman et al. proposed a data collection algorithm in IoT [20]. The proposed algorithm was aimed at maximizing throughput and reducing traffic congestion during data collection. The result shows that the algorithm performance was promising. In another approach presented by Plageras et al., proposed a novel system to gather and maintain sensors' data in smart buildings that functions in an IoT environment [38]. The result shows that the proposed system is useful. Luo et al. proposed a framework, named Privacy Protector to offer guard to patients' data during data transmission in IoT infrastructure [96]. The proposed framework includes secret sharing and shares repairing for lost patents' data. The performance analysis indicates that the proposed framework is secured and effective. Another privacy-based data collection framework was proposed by Usman et al. [97]. The result reveals that the proposed framework can be beneficial in collecting multimedia data in applications. Sun et al. offered an algorithm for data gathering to tackle the issue of fast network energy enervation and untrustworthy links on data congregation in IoT [19]. The result shows that the proposed algorithm is valid and operative paralleled to existing works. In another study by Goudarzi et al., the authors proposed a novel path planning algorithm that uses a quick and smooth data collection 
TABLE 7: Data Collection in Sensor Cloud

\begin{tabular}{|c|c|c|c|c|}
\hline Ref & Year & Proposal & Advantage & Weakness \\
\hline $\begin{array}{l}\text { Bhunia } \\
\text { et al. } \\
\text { [51] }\end{array}$ & 2014 & $\begin{array}{l}\text { The authors proposed an event driven } \\
\text { data collection scheme in sensor- } \\
\text { cloud infrastructure That makes use } \\
\text { of fuzzy logic to guarantee efficient } \\
\text { data collection and reporting. }\end{array}$ & $\begin{array}{l}\text { - Accurate decision making } \\
\text { - Good handling of uncer- } \\
\text { tainty in data }\end{array}$ & $\begin{array}{l}\text { - Lack of cross comparison } \\
\text { of the proposed scheme } \\
\text { - Without considering En- } \\
\text { ergy consumption }\end{array}$ \\
\hline $\begin{array}{l}\text { Chatterjee } \\
\text { et al. } \\
{[85]}\end{array}$ & 2015 & $\begin{array}{l}\text { The authors introduce the use of a } \\
\text { general pairwise choice framework } \\
\text { over virtual sensor networks (VSNs) } \\
\text { to deal with the issue of data transmis- } \\
\text { sion from WSNs to the cloud. }\end{array}$ & - Less energy consumption & $\begin{array}{l}\text { - Without considering packet } \\
\text { loss }\end{array}$ \\
\hline $\begin{array}{l}\text { Songar } \\
\text { and } \\
\text { Uthra } \\
{[86]}\end{array}$ & 2015 & $\begin{array}{l}\text { The authors proposed a new energy- } \\
\text { efficient routing protocol for WSN so } \\
\text { as to save nodes' energy and also in- } \\
\text { tegrate WSN with cloud. }\end{array}$ & $\begin{array}{l}\text { - High scalability } \\
\text { - High storage capacity }\end{array}$ & $\begin{array}{l}\text { - High energy consumption } \\
\text { - High latency }\end{array}$ \\
\hline $\begin{array}{l}\text { Wang et } \\
\text { al. [47] }\end{array}$ & 2016 & $\begin{array}{l}\text { A fog structure was proposed that } \\
\text { composed of multiple mobile sinks }\end{array}$ & $\begin{array}{l}\text { - Minimize transmission la- } \\
\text { tency } \\
\text { - High throughput }\end{array}$ & $\begin{array}{l}\text { - Without considering packet } \\
\text { loss } \\
\text { - High transmission overhead }\end{array}$ \\
\hline $\begin{array}{l}\text { Li et al. } \\
\text { [87] }\end{array}$ & 2016 & $\begin{array}{l}\text { The authors design an algorithm for } \\
\text { the scheduling of multiple mobile } \\
\text { sinks. }\end{array}$ & $\begin{array}{l}\text { - Less energy consumption } \\
\text { - Good data transmission }\end{array}$ & $\begin{array}{l}\text { - Without considering packet } \\
\text { loss } \\
\text { - High latency }\end{array}$ \\
\hline $\begin{array}{l}\text { Capponi } \\
\text { et al. } \\
\text { et }\end{array}$ & 2017 & $\begin{array}{l}\text { The authors proposed a novel dis- } \\
\text { tributed framework for data collection } \\
\text { in the opportunistic mobile crowd- } \\
\text { sensing system. }\end{array}$ & $\begin{array}{l}\text { - High scalability } \\
\text { - Less energy consumption }\end{array}$ & $\begin{array}{l}\text { - Without considering packet } \\
\text { loss } \\
\text { - High transmission overhead }\end{array}$ \\
\hline $\begin{array}{l}\text { Wang et } \\
\text { al. [89] }\end{array}$ & 2017 & $\begin{array}{l}\text { The authors proposed the use of mul- } \\
\text { tiple mobile sinks to aid with data } \\
\text { collection in sensor-cloud integration. }\end{array}$ & $\begin{array}{l}\text { - Good result on energy con- } \\
\text { sumption } \\
\text { - Less delivery delay }\end{array}$ & - High latency \\
\hline $\begin{array}{l}\text { Wang et } \\
\text { al. [13] }\end{array}$ & 2017 & $\begin{array}{l}\text { The authors proposed a fog structure } \\
\text { that is composed of multiple mobile } \\
\text { sinks. }\end{array}$ & $\begin{array}{l}\text { - Good result on energy con- } \\
\text { sumption } \\
\text { - Reduce transmission delay } \\
\text { - Improved throughput }\end{array}$ & $\begin{array}{l}\text { - High latency } \\
\text { - Low scalability }\end{array}$ \\
\hline $\begin{array}{l}\text { Liang et } \\
\text { al. [2] }\end{array}$ & 2019 & $\begin{array}{l}\text { The authors proposed a distributed in- } \\
\text { telligent algorithm based on a Hun- } \\
\text { garian method was proposed to ad- } \\
\text { dress the issue of transmission delay } \\
\text { and high energy consumption of fog } \\
\text { nodes }\end{array}$ & $\begin{array}{l}\text { - Low delay } \\
\text { - Less energy consumption }\end{array}$ & - Low scalability \\
\hline $\begin{array}{l}\text { Chen et } \\
\text { al. [90] }\end{array}$ & 2018 & $\begin{array}{l}\text { The authors proposed a fog } \\
\text { computing-based } \\
\text { compressive data collection scheme }\end{array}$ & $\begin{array}{l}\text { - High reconstruction quality } \\
\text { - Achieved good compression } \\
\text { gain }\end{array}$ & $\begin{array}{l}\text { - Energy consumption not } \\
\text { considered } \\
\text { - High transmission overhead }\end{array}$ \\
\hline $\begin{array}{l}\text { Wang et } \\
\text { al. [12] }\end{array}$ & 2018 & $\begin{array}{l}\text { A data collection approach named a } \\
\text { comprehensive trustworthy data col- } \\
\text { lection approach (CTDC) for sensor- } \\
\text { cloud systems was proposed }\end{array}$ & $\begin{array}{l}\text { - Effective identification of } \\
\text { malicious nodes } \\
\text { - Good energy consumption } \\
\text { - Good throughput }\end{array}$ & $\begin{array}{l}\text { - High latency } \\
\text { - High scalability } \\
\text { - High Transmission over- } \\
\text { head } \quad \text { volume } 4,2016\end{array}$ \\
\hline
\end{tabular}




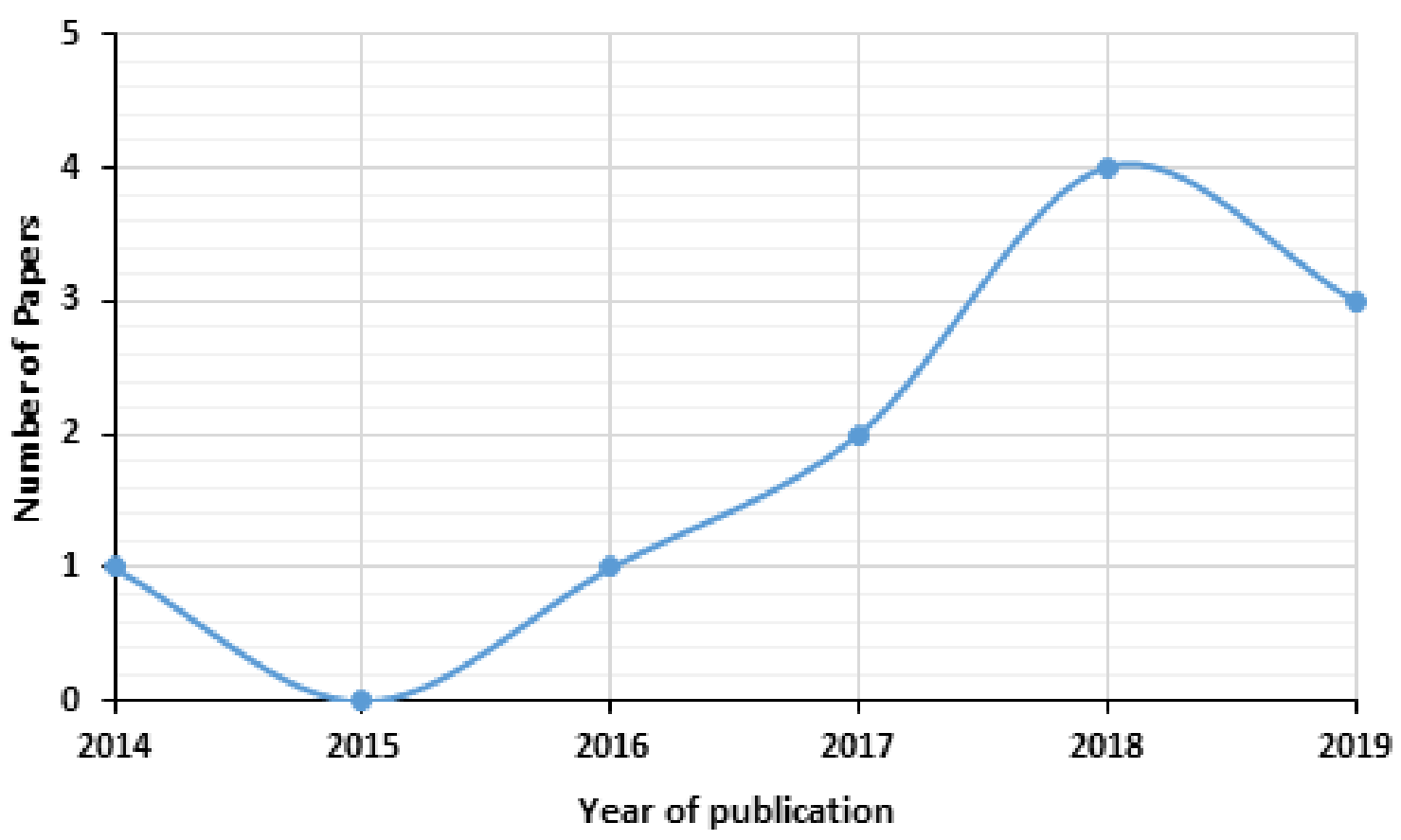

FIGURE 6: Trend in Publication for Data Collection in loT

route for Unmanned Aerial Vehicle (UAV) movements with turning limitations [98]. The algorithm was proposed to alleviate the issue of high energy lost during data collection in IoT applications. The proposed algorithm demonstrates fast data collection capabilities with low energy consumption in comparison to other solutions. In Table 8, the merits and weaknesses of each examined proposal in this section are outlined.

Lesson Learned

\section{1) Essentiality and Challenges of data collection in IOT}

In a smart city, millions of sensors are deployed in various intelligent applications like smart homes, smart transportation, smart industries, smart parking, and so forth to make the city smarter and efficient. These applications Continuously generate a huge amount of data to provide innovative services to citizens. Therefore, an efficient collection of this data is utmost important to make an effective decision for the betterment of society. The sensor nodes work in collaboration to send the collected data to the base station. In WSN, the sensor nodes have resource constraints like low power and limited communication range. So, as a result, in reference to sensor processing, the continuous stream of data generated by sensor nodes need to be processed and delivered to the end-user in the optimal lapse of time. [99]

\section{ROUTING PROTOCOL FOR DATA COLLECTION}

In this section, studies that proposed routing protocols specifically to aid in data collection in WSNs are highlighted. From
Table 9, nine studies were identified that proposed routing protocols. The table gives the merits and demerits of each proposed protocol with respect to their publication year. In an early study by Guravaiah and Velusamy, the authors proposed a routing protocol named River Formation Dynamics based Multi-hop Routing Protocol (RFDMRP) [52]. This protocol accomplishes good performance with regards to energy consumption and data transfer. Another study by Hasnain et al., the authors proposed a routing scheme for WSNs so as to guarantee dependable data communication with effective node battery dissipation [56]. The algorithm also achieves good results. Hence, of recent, routing protocols for underwater WSNs was proposed [59]. The protocol shows good performance in terms of energy usage with reliable packet transfer. However, the protocol suffers from high delay 


\section{USE CASES OF DATA COLLECTION IN DIFFERENT MODEL}

In this section, the use cases of data collection in different application scenarios are presented. The main aim is to show how data are collected and stored in WSNs, Sensor cloud, and IoT models. Table 10 gives a summary of the use cases.

\section{A. AGRICULTURE SECTOR}

Wireless sensors can be used and are used in the arena of agriculture to basically observe crops development. Whereby small sensors are embedded into plant crops so as to determine the vital stages of plant growth. With this, data collection from these sensors is vital to get information very fast with minimal energy consumption and reliable data transfer. These sensors provide farmers with information such as water shortages, sun rays, insect infections, and climate changes. Data is evaluated to provide ideal agricultural solutions for plants.

\section{B. HEALTH SECTOR}

In the health sector, centralized services were given using sensor cloud infrastructure. For example, Google provides health information with personal health data storage for its users. The users can observe their personal health data by signing into their respective accounts at a cloud health service provider into the Google health system. Microsoft also has a cloud platform named Health-Vault. Health-Vault is used to store and sustain health-related data for its users. The platform aids users to save, collect, and share their wellbeing data. The platform data can be accessed from various pharmacies, health employees, health labs, and cloud providers.

\section{MILITARY USE}

In the military, WSNs are utilized for surveilling battlefield, monitoring enemy forces, biological and chemical attack detection, and so on [100]. These sensitive data collected are very important and require high level of security that might not be provided by ordinary internet connectivity. Sensor cloud can be one of the solutions for this issue by giving a well-protected infrastructure solely for military application [101].

\section{GOVERNMENT SECTOR}

Transparency in government is vital, and throughout the world, the demand for transparency in government is increasing. Public authorities across the world have adopted eGovernance so as to enhance effectiveness in service delivery, reduces corruption, and reduce cost. Countries like USA and UK have made the cloud as an integral part of the government's IT strategy. Hence, they are moving towards a completely paperless government. However, despite this shift, traditional model of governance is gaining traction in countries like India, Pakistan, and Nigeria. This model limits the process of bringing government services closer to the people and gives rise to corruption, inefficiencies in operation, bad communication, data losses and duplications, and high cost. The sensor cloud provides more flexibility to governments' agencies to provide good services with a centralized pool of computing resources. With these benefits, the cloud has gained the attention of governments' agencies around the world.

\section{E. UNDERWATER WORLD}

Sensors are also installed underwater so as to collect and transfer data to sensor cloud. They are installed for the sole purpose of determining the pressure, barometer, water level, and sound effects. This data is vital in defining how efficiently wireless communication can happen under water.

\section{F. TRANSPORT MONITORING}

There are different transport monitoring systems, such as navigation, traffic signal control, automatic number plate recognition, emergency vehicle notification, and toll collection system. In these systems, sensors are utilized to spot automobiles and regulate traffic lights. Hence, video cameras are utilized to surveil road sections that has heavy traffic. Sensors can also be deployed at road connections to spot and count vehicle traffic for speed estimation. The data gathered from the sensors will be transmitted for central fusion and processing.

\section{G. WEARABLE DEVICES}

These devices are utilized to surveil the health of patients or to track criminal offenders. Patients can be monitor based on their sleeping, movements, walking, and so on, so as to track their health recovery developments. Criminal offenders under house arrest can also be tracked based on the location they are so as to monitor their movements at all time. Data are gathered from wearable devices through ultra-wide-band and Bluetooth wireless interfaces. The data is later kept in a WSN or sensor cloud.

\section{H. TEMPERATURE MONITORING}

Temperature is normally checked in tourist spaces to inspire tourist to be present at a seasonal and non-seasonal event. In this case, sensors are installed to give temperature data to the WSNs or sensor cloud for appropriate decision-making concerning tourism. These decisions may comprise of hotel management, visiting time, and the choice of clothes.

\section{OPEN CHALLENGES AND FUTURE DIRECTION}

This part outline the identified important study challenges in this area. Moreover, the future research directions were also given. Due to the multi-facet nature of this works, the research challenges together with future directions of specific issues are discussed in each separate bullet points. Issues such as big data collection in sensor cloud, sensor node deployment in sensor cloud, data security issues in sensor cloud, data aggregation issues in sensor cloud, dissemination of control message in sensor cloud, on-time data delivery issues in sensor cloud, data collection delay in sensor cloud, energy issues in sensor cloud, data communication issues in 
TABLE 8: Data Collection in loT

\begin{tabular}{|c|c|c|c|c|}
\hline Ref & Year & Proposal & Advantage & Weakness \\
\hline $\begin{array}{l}\text { Cecchinel } \\
\text { et al. [92] }\end{array}$ & 2014 & $\begin{array}{l}\text { The authors define software architec- } \\
\text { ture so as to support the collection of } \\
\text { sensor based data in IoT context. }\end{array}$ & - High scalability & $\begin{array}{l}\text { - high transmission over- } \\
\text { head } \\
\text { - Energy consumption not } \\
\text { considered }\end{array}$ \\
\hline $\begin{array}{l}\text { Shi et al. } \\
\text { [93] }\end{array}$ & 2016 & $\begin{array}{l}\text { A system named Opportunistic Net- } \\
\text { working Connectivity Service (Opp- } \\
\text { Net) was proposed. }\end{array}$ & - Low delay & - High latency \\
\hline $\begin{array}{l}\mathrm{Xu} \text { et al. } \\
{[23]}\end{array}$ & 2017 & $\begin{array}{l}\text { The authors proposed a distributed al- } \\
\text { gorithm named EQRoute. }\end{array}$ & $\begin{array}{l}\text { - Good scalability } \\
\text { - High packet delivery }\end{array}$ & - High delay \\
\hline $\begin{array}{l}\text { Zhu et al. } \\
\text { [94] }\end{array}$ & 2017 & $\begin{array}{l}\text { The authors developed a two-phase ap- } \\
\text { proach to help in managing data upload } \\
\text { for mobile data collectors. }\end{array}$ & $\begin{array}{l}\text { - Improved overall data } \\
\text { utility } \\
\text { - Low data collection de- } \\
\text { lay } \\
\text { - High scalability }\end{array}$ & $\begin{array}{l}\text { - High transmission over- } \\
\text { head }\end{array}$ \\
\hline $\begin{array}{l}\text { Fan et al. } \\
{[95]}\end{array}$ & 2018 & $\begin{array}{l}\text { The authors proposed a workload bal- } \\
\text { ancing scheme in fog network so as } \\
\text { to minimize data flow latency during } \\
\text { communications and processing with } \\
\text { IoT devices to suitable Base Stations. }\end{array}$ & - Low latency & $\begin{array}{l}\text { - Low scalability } \\
\text { - Energy consumption not } \\
\text { considered }\end{array}$ \\
\hline $\begin{array}{l}\text { Rahman et } \\
\text { al. [20] }\end{array}$ & 2018 & $\begin{array}{l}\text { The authors proposed an algorithm } \\
\text { named consistent data collection and } \\
\text { assortment in the progression of contin- } \\
\text { uous objects in IoT (CDCAPC). }\end{array}$ & $\begin{array}{l}\text { - Low data loss } \\
\text { - Low delay } \\
\text { - High priority data de- } \\
\text { livery }\end{array}$ & $\begin{array}{l}\text { - Low scalability } \\
\text { - Energy consumption not } \\
\text { considered }\end{array}$ \\
\hline $\begin{array}{l}\text { Plageras } \\
\text { et al. [38] }\end{array}$ & 2018 & $\begin{array}{l}\text { The authors proposed a new system } \\
\text { to collect and manage sensors' data in } \\
\text { smart buildings that functions in an IoT } \\
\text { environment. }\end{array}$ & $\begin{array}{l}\text { - Low energy consump- } \\
\text { tion }\end{array}$ & $\begin{array}{l}\text { - High transmission over- } \\
\text { head }\end{array}$ \\
\hline $\begin{array}{l}\text { Luo et al. } \\
\text { [96] }\end{array}$ & 2018 & $\begin{array}{l}\text { The authors proposed a framework, } \\
\text { named PrivacyProtector to provide pro- } \\
\text { tection to patients' data during data } \\
\text { transmission in IoT infrastructure. }\end{array}$ & $\begin{array}{l}\text { - High security } \\
\text { - High privacy }\end{array}$ & $\begin{array}{l}\text { - Low scalability } \\
\text { - High energy consump- } \\
\text { tion }\end{array}$ \\
\hline $\begin{array}{l}\text { Usman et } \\
\text { al. [97] }\end{array}$ & 2019 & $\begin{array}{l}\text { The authors proposed a framework } \\
\text { named efficient privacy-preserving- } \\
\text { based data collection and analysis } \\
\text { (P2DCA) for the internet of multimedia } \\
\text { things (IOMT) applications. }\end{array}$ & $\begin{array}{l}\text { - High security } \\
\text { - High privacy }\end{array}$ & $\begin{array}{l}\text { - Low scalability } \\
\text { - High energy consump- } \\
\text { tion }\end{array}$ \\
\hline $\begin{array}{l}\text { Sun et al. } \\
\text { [19] }\end{array}$ & 2019 & $\begin{array}{l}\text { The authors proposed an algorithm, } \\
\text { named mobile intelligent computing } \\
\text { based on compressive sensing data } \\
\text { gathering (MIC-CSDG) to tackle the } \\
\text { issue of fast network energy exhaustion } \\
\text { and unreliable links on data gathering } \\
\text { in IoT. }\end{array}$ & $\begin{array}{l}\text { - Low energy consump- } \\
\text { tion } \\
\text { - Minimal data forward- } \\
\text { ing time }\end{array}$ & - Low scalability \\
\hline $\begin{array}{l}\text { Goudarzi } \\
\text { et al. [98] }\end{array}$ & 2019 & $\begin{array}{l}\text { The authors proposed a new path plan- } \\
\text { ning algorithm that uses a short and } \\
\text { smooth data collection path for Un- } \\
\text { manned Aerial Vehicle (UAV) move- } \\
\text { ments with turning constraints. }\end{array}$ & $\begin{array}{l}\text { - Fast data collection } \\
\text { - High delivery rate } \\
\text { - Low energy usage }\end{array}$ & $\begin{array}{l}\text { - high transmission over- } \\
\text { head } \\
\text { - low scalability } \\
\text { - high latency }\end{array}$ \\
\hline
\end{tabular}


TABLE 9: Routing protocol for Data Collection

\begin{tabular}{|c|c|c|c|c|}
\hline Ref & Year & Proposal & Merits & Demerits \\
\hline [52] & 2015 & $\begin{array}{l}\text { The authors proposed a routing protocol named } \\
\text { River Formation Dynamics based Multi-hop } \\
\text { Routing Protocol (RFDMRP) }\end{array}$ & $\begin{array}{l}\text { - Performs better } \\
\text { than LEACH and } \\
\text { MODLEACH routing } \\
\text { protocols } \\
\text { - Good result on energy } \\
\text { consumption and net- } \\
\text { work lifetime } \\
\text { - Good data transfer }\end{array}$ & $\begin{array}{l}\text { Only considers hop } \\
\text { count value and resid- } \\
\text { ual energy as parame- } \\
\text { ters for forward node } \\
\text { selection }\end{array}$ \\
\hline [56] & 2018 & $\begin{array}{l}\text { The authors proposed an opportunistic routing } \\
\text { scheme for WSNs so as to guarantee dependable } \\
\text { data communication with effective node battery } \\
\text { dissipation }\end{array}$ & $\begin{array}{l}\text { - Achieves good results on } \\
\text { energy and packet deliv- } \\
\text { ery ratio. }\end{array}$ & $\begin{array}{l}\text { - Node closer to sink } \\
\text { can face higher data } \\
\text { traffic due to sudden } \\
\text { death of node in the } \\
\text { network. }\end{array}$ \\
\hline [57] & 2018 & $\begin{array}{l}\text { The authors proposed a new data collection } \\
\text { scheme named ring topology based compressive } \\
\text { sensing data collection scheme (RTCS) }\end{array}$ & $\begin{array}{l}\text { - Achieves good in matrix } \\
\text { measurement } \\
\text { - Enhances the accuracy } \\
\text { of data delivery } \\
\text { - Lower energy consump- } \\
\text { tion }\end{array}$ & $\begin{array}{l}\text { - No priority is given to } \\
\text { data delivery ratio. }\end{array}$ \\
\hline [74] & 2017 & $\begin{array}{l}\text { The authors proposed two routing algorithms, } \\
\text { named Trail-based Algorithm with Virtual Guide } \\
\text { Line (TAG) and enhanced Trail-based Algorithm } \\
\text { with Virtual Guide Line (eTAG) }\end{array}$ & $\begin{array}{l}\text { - Reduces the average for- } \\
\text { warding hop counts of } \\
\text { data packets. } \\
\text { - Ensures all source } \\
\text { sensors find the mobile } \\
\text { sinks }\end{array}$ & $\begin{array}{l}\text { - Network lifetime and } \\
\text { energy consumption } \\
\text { was not considered } \\
\text { for evaluation }\end{array}$ \\
\hline [80] & 2018 & $\begin{array}{l}\text { The authors proposed an energy-efficient routing } \\
\text { clustering algorithm for wireless sensor networks }\end{array}$ & $\begin{array}{l}\text { - Good result on network } \\
\text { lifetime }\end{array}$ & $\begin{array}{l}\text { - Poor energy } \\
\text { consumption }\end{array}$ \\
\hline [79] & 2017 & $\begin{array}{l}\text { The authors proposed an energy-efficient routing } \\
\text { mechanism with deliberate mobility to wireless } \\
\text { sensor networks with obstacles }\end{array}$ & $\begin{array}{l}\text { - Less energy consump- } \\
\text { tion } \\
\text { - Longer network lifetime }\end{array}$ & $\begin{array}{l}\text { - Obstacle-avoiding } \\
\text { shortest tour problem } \\
\text { was not addressed }\end{array}$ \\
\hline [39] & 2018 & $\begin{array}{l}\text { Proposed a novel data gathering protocol for } \\
\text { wireless sensor networks smart grid applications, } \\
\text { named multi-mobile sinksbased QoS-aware data } \\
\text { gathering aware routing protocol (MQRP) }\end{array}$ & $\begin{array}{l}\text { - Improve region-based } \\
\text { coverage issues } \\
\text { - Avoids nodes buffer } \\
\text { overflow time } \\
\text { - Reduce latency }\end{array}$ & $\begin{array}{l}\text { - Relatively higher en- } \\
\text { ergy consumption in } \\
\text { comparison to exist- } \\
\text { ing works }\end{array}$ \\
\hline [86] & 2015 & $\begin{array}{l}\text { The authors proposed a new energy-efficient rout- } \\
\text { ing protocol for WSN so as to save nodes' energy } \\
\text { and also integrate WSN with cloud }\end{array}$ & $\begin{array}{l}\text { - Good performance in } \\
\text { comparison to existing } \\
\text { works }\end{array}$ & $\begin{array}{l}\text { - No priority is given to } \\
\text { data delivery ratio and } \\
\text { energy consumption }\end{array}$ \\
\hline [59] & 2019 & $\begin{array}{l}\text { The authors proposed two routing protocols for } \\
\text { underwater WSNs named effective energy and re- } \\
\text { liable delivery (EERD) and cooperative effective } \\
\text { energy and reliable delivery (CoEERD). }\end{array}$ & $\begin{array}{l}\text { - Good performance in en- } \\
\text { ergy usage } \\
\text { - Reliable packet transfer }\end{array}$ & $\begin{array}{l}\text { - High delay } \\
\qquad \text { volume } 4,2016\end{array}$ \\
\hline
\end{tabular}




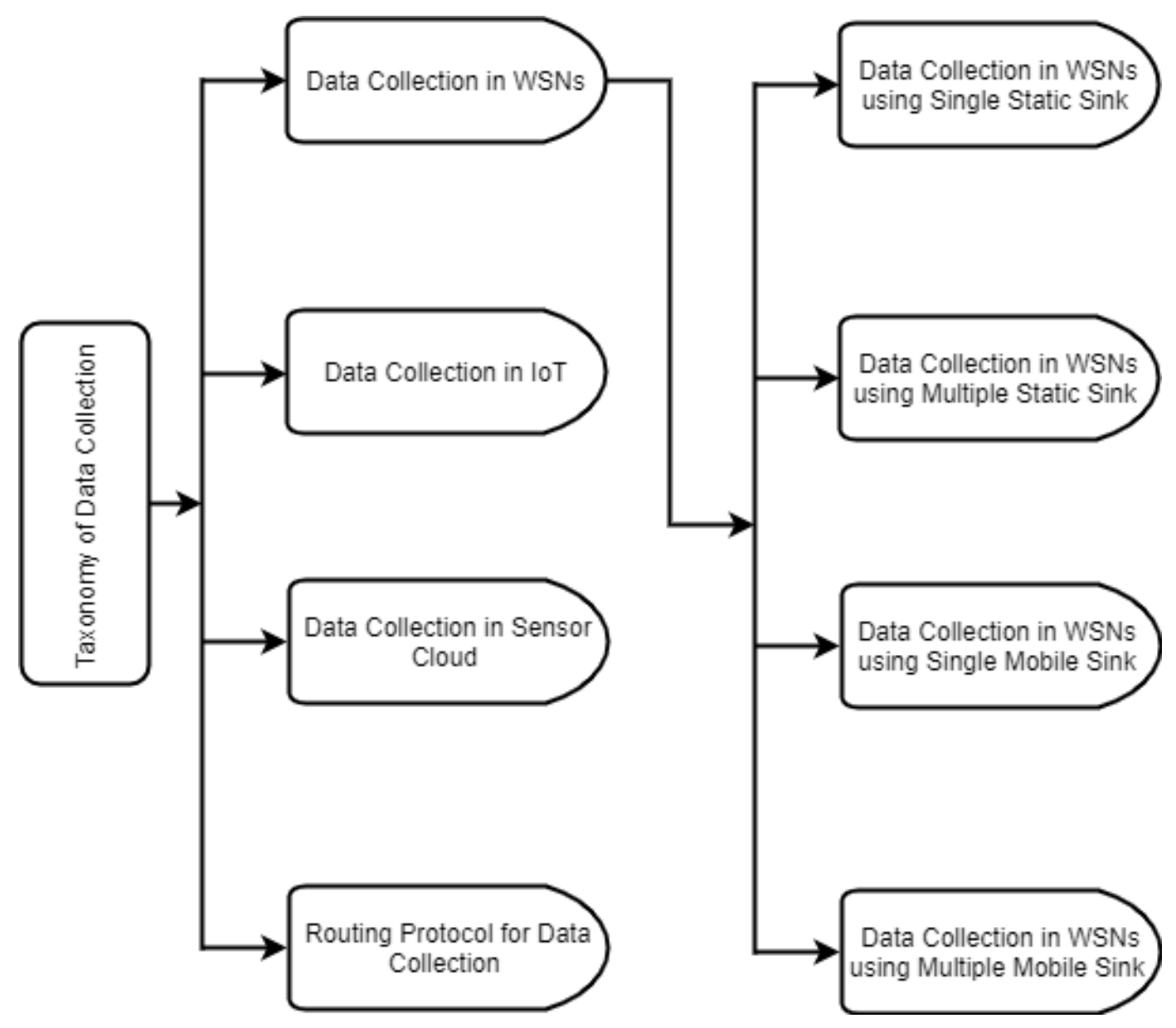

FIGURE 7: Taxonomy of Data Collection

sensor cloud, and quality of service (QoS) data collections issues in sensor-cloud.

\section{A. BIG DATA COLLECTION ISSUE IN SENSOR CLOUD}

The perception of big data is supported by the manifestation of new innovations with heterogeneous framework. The appropriation of new innovations in our daily lives results to the consistent increase in data day by day. This occurrence happens in WSNs, particularly in Sensor Cloud. Various points in sensor cloud produce a difficult environment for data collection in WSNs. Hence, sensor nodes are the key source of this big data are needed to be collected and transferred to the cloud on time [51]. Sensor system have a weak ability to transfer a vast amount of information to the cloud, therefore, this procedure might not work effectively. Furthermore, the multiplicity of data produced through many devices in sensor cloud obscures the data collection method. Hence, some devices might send the information speedily, while others devices might send the data slowly. This will result the postponement of the whole procedure. Additionally, the significance of the data sorts the information gathering procedure challenging, due to the fact that the amount of users surges which eventually producing more values. When the amount of users rises the value of data, hence, necessitates the data collection procedure to be optimum ample in other to manage in a complicated situation.

\section{B. SENSOR NODE DEPLOYMENT ISSUE IN SENSOR CLOUD}

In sensor cloud, there are sensor node's deployment issues. This issue in data collection is in a situation that the sensor nodes has to be deployed in a close location of the event to allow for an efficient data collection process. The sensor nodes that are installed near the cloud accumulate data faster than the sensor nodes positioned far away from the cloud. Thus, this produces a data reliance issue when transferring information to the cloud. However, this issue increased for smart city, where devices are disseminated far from each other. Hence, in other to resolve this issue, smart city need to embrace best practices from WSN and cloud computing domain.

\section{DATA SECURITY ISSUE IN SENSOR CLOUD:}

To store sense data particularly in smart city, a good protection is essential so as to store the information in the cloud. There are three aspect of securing the collected data. The first one is during collection then during transmission to the 
TABLE 10: Summary of the Use Cases in Data Collection

\begin{tabular}{|c|c|c|}
\hline $\mathbf{S} / \mathbf{N}$ & Use Cases & Role \\
\hline 1 & Agriculture sector & $\begin{array}{l}\text { - Help in monitoring plants health, water level, insect inspection, sun rays, and } \\
\text { climate change. } \\
\text { - Help to alert the farmer to take the necessary measures when required. }\end{array}$ \\
\hline 2 & Health sector & $\begin{array}{l}\text { - Help to provide health information with data storage for users. } \\
\text { - Help users to remotely monitor their health records. }\end{array}$ \\
\hline 3 & Military use & $\begin{array}{l}\text { - Help in surveilling battlefield. } \\
\text { - Help in monitoring enemy forces. }\end{array}$ \\
\hline 4 & Government sector & $\begin{array}{l}\text { - Help to reduce corruption and to improve transparency in governance. } \\
\text { - Help to enhance the delivery of government services. } \\
\text { - Help to reduce the cost of governance. }\end{array}$ \\
\hline 5 & Underwater world & $\begin{array}{l}\text { - Aid in storing, processing, and analyzing data efficiently. } \\
\text { - Aid in discovering the temperature of water, oxygen level in water, and bacterial } \\
\text { contents. }\end{array}$ \\
\hline 6 & $\begin{array}{l}\text { Transportation } \\
\text { monitoring }\end{array}$ & $\begin{array}{l}\text { - Helps in surveilling road sections with heavy traffic. } \\
\text { - Helps in tracking the vehicles easily }\end{array}$ \\
\hline 7 & Wearable devices & $\begin{array}{l}\text { - Help in processing and examining the collected data efficiently. } \\
\text { - Helps doctors and nurses to monitor and deliver on-time treatment to patients. } \\
\text { - Helps law enforcement to track the movements of violent criminal offenders } \\
\text { under house arrest. }\end{array}$ \\
\hline 8 & $\begin{array}{l}\text { Temperature } \\
\text { monitoring }\end{array}$ & $\begin{array}{l}\text { - Aid in analyzing data on time which can result in life-saving in diverse areas. } \\
\text { - Offers real-time data gathering and analyses services. }\end{array}$ \\
\hline
\end{tabular}

cloud and then after storing these data in the cloud .The collected data from different sensors need to be adequately protected before transmitting to the cloud, then it is stored in the cloud. The most difficult tasks in data collection is to guarantee where security ought to be employed. Besides, ensuring information security at WSNs is trying due of the restricted resources of sensor nodes. On the other hand, employing information security in a sensor cloud do not guarantee that information sent to the cloud are unaltered during transmission. For data gathering in smart city, one has to ensure a reliable and safer way of data collection. Therefore, to resolve this issue, one has to install a secure middle-ware application between sensor nodes and the cloud. Thus, information can be searched based on the defined security bounds before transferring them to the cloud.

\section{DATA AGGREGATION ISSUE IN SENSOR CLOUD}

The amalgamation of data from numerous sources before sending it to the base stations is very difficult, particularly in smart city. In smart city, there are enormous amount of nodes that help in the transmission of data to base stations. However, these base stations are have low storage capabilities to store all data in their memory. With this condition, the data can be released, which will result in the cost of data reliability. The data aggregation issue comes into play whenever the amount of data nodes is amplified, which typically happens in smart city because of the huge amount of sensor nodes deployed. This problem might be reduced by introducing the categorization of collected data based on the nature of the collected data, which will permit for easy storing and accessing of the collected data in the sensor cloud paradigm. 


\section{E. DATA COLLECTION DELAY IN SENSOR-CLOUD}

As the data produced by the sensor node in WSNs is collected by MS in most of the cases. MS sink then upload this data to the cloud which takes time due to large amount of data uploading in some time critical application such as health related issue the delay in the collected data is not affordable which will affect the human life lose directly. Such delay needs to be reduced that the doctor can take decision on timely manner to tackle the patient critical situation to save the life of a patient. In other example the delay incurred in the data collection in the fire detection application is also critical which can save the catastrophe situation occurred in the case of fire.

\section{F. ENERGY RELATED ISSUE IN SENSOR-CLOUD}

Looking at a tourism navigation application that directs a user to stride straight to a particular touring place, this kind of application may be beneficial if the user is nearby the tourism area. However, it cannot be retrieved when the user is at home. In a nutshell, the present locations of a user generally define the precise data a mobile user may request. Most sensors are typically prepared with non-rechargeable batteries that has limited energy [35] [37] [81]. Therefore, if the sensor nodes constantly forward the received data to the cloud, the energy of these sensor nodes will be exhausted rapidly and the lifetime of the WSN reduced.

\section{G. DATA COMMUNICATION ISSUE IN SENSOR-CLOUD}

Sensor cloud applications such as for healthcare monitoring, smart home monitoring, agriculture, and much more, necessitate the WSNs to consistently provide tangible information that are increasingly beneficial to the cloud depend on the users' requirements. For instance, looking at smart house monitoring, even though numerous supervised information about the entire home are collected by the tactically installed camera sensors and different kinds of sensor data can also be transferred to the cloud so as to enable the proprietor to validated and give permission to people through their mobile devices. Because videos from sites like storage room are of little or no importance, whereas video recorder from different places like back door, front door, and windows are more significant to ensure that there is no entry of unforeseen incursion into the home. Therefore, all the tactile information are not beneficial for the cloud to fulfill customer requirements. At this point, we observed that two things. Firstly, the tactile information that are beneficial to the customers should be obtainable from WSNs to cloud. Conversely, to monitor the household wisely, the WSN necessitates to effectively gather and forward the retrieved data to the cloud constantly. This implies the tangible data should be transferred dependably from the WSNs to the cloud.

\section{H. QUALITY OF SERVICE (QOS) DATA COLLECTION ISSUE IN SENSOR-CLOUD:}

QoS is at all times a captivating and important topic, as QoS constantly shows a key part for consumers to utilize the facility. Trust should improve the performance of a current framework, by conveying trust significance to the object of the system. Possible way to increase the QoS of sensor cloud is always worth to be investigated.

\section{CONCLUSION}

In recent years, WSN applications have been utilized in numerous significant areas, such as weather forecasting, military, environment monitoring, healthcare, and manufacturing. In this paper, a review on data collection in WSNs, sensor cloud, and IoT was presented. Studies published in the last decade (2009 - 2019) were considered so as to aid researchers in understanding literature in the field of study. We conducted an in-depth analysis and review of relevant studies in the research domain. We also explored data collection schemes in WSNs, sensor cloud, IoT, and routing protocols for data collection. Furthermore, the use cases of data collection in different application scenarios such as agricultural sector, health sector, government sector, and so on, were presented and discussed in detail. The general taxonomy of data collection was formulated and presented in Section V. Additionally, a bibliometric overview of the literature in the research domain was explored. This will help to enlighten the new and veteran researchers in knowing the most active year in terms of publication, the most active publication channels, supported grants, countries and institutions that contributed more in the research domain. We observed that 2018 was the most active year with 25 published papers, followed by the year 2017 and 2019 with 19 and 18 papers, respectively. We also found out that IEEE Access was the most active Journal with 7 papers published in the Journal. With respect to Grants, China contributes the most with $22(47.8 \%)$ funding agencies out of the total 46 Grants identified. Hence, China has made significant contribution in terms of finances. Furthermore, China was the most active country with 43 papers, followed by USA (14), and India (10), respectively. Lastly the identified challenges and future directions in the research domain were also highlighted in Section VII. For future works, we encourage both new and veteran researchers to give critical attention and effort in addressing the challenges identified. 


\section{REFERENCES}

[1] Y. Liu, K.-Y. Lam, S. Han, and Q. Chen, "Mobile data gathering and energy harvesting in rechargeable wireless sensor networks," Information Sciences, vol. 482, pp. 189-209, 2019.

[2] J. Liang, Y. Long, Y. Mei, T. Wang, and Q. Jin, "A distributed intelligent hungarian algorithm for workload balance in sensor-cloud systems based on urban fog computing," IEEE Access, vol. 7, pp. 77 649-77 658, 2019.

[3] I. Ali, A. Gani, I. Ahmedy, I. Yaqoob, S. Khan, and M. H. Anisi, "Data collection in smart communities using sensor cloud: recent advances, taxonomy, and future research directions," IEEE Communications Magazine, vol. 56, no. 7, pp. 192-197, 2018.

[4] S. K. Singh and P. Kumar, "A comprehensive survey on trajectory schemes for data collection using mobile elements in wsns," Journal of Ambient Intelligence and Humanized Computing, vol. 11, no. 1, pp. 291312, 2020.

[5] S. R. Wankhade and N. A. Chavhan, "A review on data collection method with sink node in wireless sensor network," International Journal of Distributed and Parallel Systems (IJDPS), vol. 4, no. 1, pp. 67-74, 2013.

[6] A. W. Khan, A. H. Abdullah, M. H. Anisi, and J. I. Bangash, "A comprehensive study of data collection schemes using mobile sinks in wireless sensor networks," Sensors, vol. 14, no. 2, pp. 2510-2548, 2014.

[7] M. Di Francesco, S. K. Das, and G. Anastasi, "Data collection in wireless sensor networks with mobile elements: A survey," ACM Transactions on Sensor Networks (TOSN), vol. 8, no. 1, pp. 1-31, 2011

[8] H. Yetgin, K. T. K. Cheung, M. El-Hajjar, and L. H. Hanzo, "A survey of network lifetime maximization techniques in wireless sensor networks," IEEE Communications Surveys \& Tutorials, vol. 19, no. 2, pp. 828-854, 2017.

[9] M. Z. Hasan, H. Al-Rizzo, and F. Al-Turjman, "A survey on multipath routing protocols for qos assurances in real-time wireless multimedia sensor networks," IEEE Communications Surveys \& Tutorials, vol. 19, no. 3, pp. 1424-1456, 2017.

[10] K. A. Waghmare and D. P. Chat, "Energy efficient data collection and routing algorithm in wireless sensor network: A survey," IJREST. NET, vol. 1, no. 2, 2014.

[11] N. M. Nair and A. F. A. Jose, "Survey on data collection methods in wireless sensor networks," International Journal of Engineering Research \& Technology (IJERT), 2013.

[12] T. Wang, Y. Li, W. Fang, W. Xu, J. Liang, Y. Chen, and X. Liu, "A comprehensive trustworthy data collection approach in sensor-cloud system," IEEE Transactions on Big Data, 2018.

[13] T. Wang, J. Zeng, Y. Lai, Y. Cai, H. Tian, Y. Chen, and B. Wang, "Data collection from wsns to the cloud based on mobile fog elements," Future Generation Computer Systems, 2017.

[14] S. Biswas, R. Das, and P. Chatterjee, "Energy-efficient connected target coverage in multi-hop wireless sensor networks," in Industry interactive innovations in science, engineering and technology. Springer, 2018, pp. 411-421.

[15] H. Salarian, K.-W. Chin, and F. Naghdy, "An energy-efficient mobile-sink path selection strategy for wireless sensor networks," IEEE Transactions on vehicular technology, vol. 63, no. 5, pp. 2407-2419, 2013.

[16] H. Huang and A. V. Savkin, "An energy efficient approach for data collection in wireless sensor networks using public transportation vehicles," AEU-International Journal of Electronics and Communications, vol. 75, pp. 108-118, 2017.

[17] Q. Wang, W. Liu, T. Wang, M. Zhao, X. Li, M. Xie, M. Ma, G. Zhang, and A. Liu, "Reducing delay and maximizing lifetime for wireless sensor networks with dynamic traffic patterns," IEEE Access, vol. 7, pp. $70212-$ $70236,2019$.

[18] J. Tan, W. Liu, T. Wang, N. N. Xiong, H. Song, A. Liu, and Z. Zeng, “An adaptive collection scheme-based matrix completion for data gathering in energy-harvesting wireless sensor networks," IEEE Access, vol. 7, pp. 6703-6723, 2019.

[19] Z. Sun, X. Xing, B. Song, Y. Nie, and H. Shao, "Mobile intelligent computing in internet of things: An optimized data gathering method based on compressive sensing," IEEE Access, vol. 7, pp. 66 110-66 122, 2019.

[20] T. Rahman, X. Yao, and G. Tao, "Consistent data collection and assortment in the progression of continuous objects in iot," IEEE Access, vol. 6, pp. 51 875-51 885, 2018.

[21] X. He, S. Liu, G. Yang, and N. Xiong, "Achieving efficient data collection in heterogeneous sensing wsns," IEEE Access, vol. 6, pp. 63 187-63 199, 2018 .
[22] S. Cai, Y. Zhu, T. Wang, G. Xu, A. Liu, and X. Liu, "Data collection in underwater sensor networks based on mobile edge computing," IEEE Access, vol. 7, pp. 65 357-65 367, 2019.

[23] G. Xu, E. C.-H. Ngai, and J. Liu, "Ubiquitous transmission of multimedia sensor data in internet of things," IEEE Internet of Things Journal, vol. 5, no. 1, pp. 403-414, 2017.

[24] G. Han, X. Yang, L. Liu, and W. Zhang, "A joint energy replenishment and data collection algorithm in wireless rechargeable sensor networks," IEEE Internet of Things Journal, vol. 5, no. 4, pp. 2596-2604, 2017.

[25] M. Dong, K. Ota, and A. Liu, "Rmer: Reliable and energy-efficient data collection for large-scale wireless sensor networks," IEEE Internet of Things Journal, vol. 3, no. 4, pp. 511-519, 2016.

[26] C.-F. Cheng and C.-F. Yu, "Mobile data gathering with bounded relay in wireless sensor networks," IEEE Internet of Things Journal, vol. 5, no. 5, pp. 3891-3907, 2018.

[27] B. Yi, M. Xiang, T. Huang, H. Huang, K. Qiu, and W. Li, "Data gathering with distributed rateless coding based on enhanced online fountain codes over wireless sensor networks," AEU-International Journal of Electronics and Communications, vol. 92, pp. 86-92, 2018.

[28] M. Krishnan, S. Yun, and Y. M. Jung, "Improved clustering with fireflyoptimization-based mobile data collector for wireless sensor networks," AEU-International Journal of Electronics and Communications, vol. 97, pp. 242-251, 2018.

[29] H. Huang, C. Huang, and D. Ma, "The cluster based compressive data collection for wireless sensor networks with a mobile sink," AEUInternational Journal of Electronics and Communications, vol. 108, pp. 206-214, 2019.

[30] A. Kaswan, K. Nitesh, and P. K. Jana, "Energy efficient path selection for mobile sink and data gathering in wireless sensor networks," AEUInternational Journal of Electronics and Communications, vol. 73, pp. 110-118, 2017.

[31] C. Zhu, S. Zhang, G. Han, J. Jiang, and J. J. Rodrigues, "A greedy scanning data collection strategy for large-scale wireless sensor networks with a mobile sink," Sensors, vol. 16, no. 9, p. 1432, 2016.

[32] S. Rashed and M. Soyturk, "Analyzing the effects of uav mobility patterns on data collection in wireless sensor networks," Sensors, vol. 17, no. 2, p. 413,2017

[33] G. Li, H. Chen, S. Peng, X. Li, C. Wang, S. Yu, and P. Yin, "A collaborative data collection scheme based on optimal clustering for wireless sensor networks," Sensors, vol. 18, no. 8, p. 2487, 2018.

[34] H. Cao, Y. Liu, X. Yue, and W. Zhu, "Cloud-assisted uav data collection for multiple emerging events in distributed wsns," Sensors, vol. 17, no. 8, p. 1818,2017

[35] P. Zhang, S. Wang, K. Guo, and J. Wang, "A secure data collection scheme based on compressive sensing in wireless sensor networks," Ad Hoc Networks, vol. 70, pp. 73-84, 2018.

[36] J. Kulshrestha and M. K. Mishra, "An adaptive energy balanced and energy efficient approach for data gathering in wireless sensor networks," Ad Hoc Networks, vol. 54, pp. 130-146, 2017.

[37] C. Caillouet, F. Giroire, and T. Razafindralambo, "Efficient data collection and tracking with flying drones," Ad Hoc Networks, vol. 89, pp. 35-46, 2019.

[38] A. P. Plageras, K. E. Psannis, C. Stergiou, H. Wang, and B. B. Gupta, "Efficient iot-based sensor big data collection-processing and analysis in smart buildings," Future Generation Computer Systems, vol. 82, pp. 349-357, 2018.

[39] M. Faheem and V. C. Gungor, "Mqrp: Mobile sinks-based qos-aware data gathering protocol for wireless sensor networks-based smart grid applications in the context of industry 4.0-based on internet of things," Future Generation Computer Systems, vol. 82, pp. 358-374, 2018.

[40] Y. Zhang, S. He, and J. Chen, "Near optimal data gathering in rechargeable sensor networks with a mobile sink," IEEE Transactions on Mobile Computing, vol. 16, no. 6, pp. 1718-1729, 2016.

[41] S. Yang, U. Adeel, Y. Tahir, and J. A. McCann, "Practical opportunistic data collection in wireless sensor networks with mobile sinks," IEEE Transactions on Mobile Computing, vol. 16, no. 5, pp. 1420-1433, 2016.

[42] K. Li, C. Yuen, B. Kusy, R. Jurdak, A. Ignjatovic, S. S. Kanhere, and S. Jha, "Fair scheduling for data collection in mobile sensor networks with energy harvesting," IEEE Transactions on Mobile Computing, vol. 18, no. 6, pp. 1274-1287, 2018.

[43] H. Teng, K. Zhang, M. Dong, K. Ota, A. Liu, M. Zhao, and T. Wang, "Adaptive transmission range based topology control scheme for fast and reliable data collection," Wireless Communications and Mobile Computing, vol. 2018, 2018. 
TABLE 11: Definitions of all acronyms mentioned in the paper

\begin{tabular}{|c|c|}
\hline \multicolumn{2}{|r|}{ Abbreviations } \\
\hline SNP & Sensor Network Provider \\
\hline CSP & Cloud Service Provider \\
\hline CSU & Cloud Service User \\
\hline RMER & Multipath Counter Routing \\
\hline URL & Unequal Redundancy Level \\
\hline MDC & Mobile Data Collector \\
\hline RTCS & Ring Topology Based Compressive Sensing Data Collection Scheme \\
\hline IWSNs & Industrial WSNs \\
\hline ADCP & Aerial Data Collection Problem \\
\hline UAVS & Unmanned Aerial Vehicles \\
\hline EERD & Effective Energy And Reliable Delivery \\
\hline COEERD & Cooperative Effective Energy And Reliable Delivery \\
\hline GBP & Global Best Path \\
\hline RPS & Rendezvous Points \\
\hline WRP & Weighted Rendezvous Planning \\
\hline RSNs & Rechargeable Sensor Networks \\
\hline DDGA & Distributed Data Gathering Approach \\
\hline CAETX & Contact-Aware ETX \\
\hline TAG & Trail-based Algorithm with Virtual Guide Line \\
\hline eTAG & enhanced Trail-Based Algorithm With Virtual Guide Line \\
\hline UAVS & Unmanned Aerial Vehicles \\
\hline RDDC & Regional Density-Aware Data Collection \\
\hline VGDCA-C & Virtual Grid-based Real-Time Data Collection Algorithm \\
\hline IWSNs & Industrial WSNs \\
\hline RDML & Reducing Delay And Maximizing Lifetime \\
\hline RWSNs & Rechargeable Wireless Sensor Networks \\
\hline MMS & Multiple Mobile Sink \\
\hline MADC & Mobility Assisted Data Collection \\
\hline WMSNs & Wireless Multimedia Sensor Networks \\
\hline MQRP & Qos-Aware Data Gathering Aware Protocol \\
\hline QoS & Quality Of Service \\
\hline VSNs & Location-Aware Routing For Controlled MS Virtual Sensor Networks $* * * *$ \\
\hline CTDC & Comprehensive Trustworthy Data Collection Approach \\
\hline GSDCS & Greedy Scanning Data Collection Strategy \\
\hline THD & Time High-Overflow-Based Dominating Algorithm \\
\hline TCM & Temporary Caching Mechanism \\
\hline DMWS & Dominating based Minimum Weighted Sum \\
\hline GBP & Global Best Path \\
\hline LAB & Load Balancing \\
\hline CTDC & Comprehensive Trustworthy Data Collection Approach \\
\hline RFDMRP & River Formation Dynamics Based Multi-Hop Routing Protocol \\
\hline CDCAPC & Consistent Data Collection And Assortment In The Progression Of Continuous Objects In IoT \\
\hline P2DCA & Privacy-Preserving-Based Data Collection And Analysis \\
\hline IOMT & Internet Of Multimedia Things \\
\hline $\begin{array}{l}\text { MICCSDG } \\
\text { UAV }\end{array}$ & $\begin{array}{l}\text { Mobile Intelligent Computing Based On Compressive Sensing Data Gathering } \\
\text { Unmanned Aerial Vehicle }\end{array}$ \\
\hline RFDMRP & River Formation Dynamics Based Multi-Hop Routing Protocol \\
\hline RTCS & Ring Topology Based Compressive Sensing Data Collection Scheme \\
\hline MQRP & Qos-Aware Data Gathering Aware Routing Protocol **** \\
\hline EERD & Effective Energy And Reliable Delivery \\
\hline COEERD & Cooperative Effective Energy And Reliable Delivery \\
\hline
\end{tabular}


[44] Z. Sun, R. Tao, N. Xiong, and X. Pan, "Cs-plm: Compressive sensing data gathering algorithm based on packet loss matching in sensor networks," Wireless Communications and Mobile Computing, vol. 2018, 2018.

[45] K. Xie, X. Ning, X. Wang, S. He, Z. Ning, X. Liu, J. Wen, and Z. Qin, "An efficient privacy-preserving compressive data gathering scheme in wsns," Information Sciences, vol. 390, pp. 82-94, 2017.

[46] C. Zhu, K. Quan, G. Han, and J. J. Rodrigues, "A high-available and location predictive data gathering scheme with mobile sinks for wireless sensor networks," Computer Networks, vol. 145, pp. 156-164, 2018.

[47] M.-S. Pan, P.-L. Liu, and Y.-P. Lin, "Event data collection in zigbee treebased wireless sensor networks," Computer Networks, vol. 73, pp. 142153, 2014.

[48] J. Wang, B. Tang, Y. Zheng, J. Zhang, and J.-U. Kim, "An efficient data gathering algorithm for wireless sensor networks with single mobile sink."

[49] L. Bagheri and M. D. T. Fooladi, "A rendezvous-based data collection algorithm with mobile sink in wireless sensor networks," in 2014 4th International Conference on Computer and Knowledge Engineering (ICCKE). IEEE, 2014, pp. 758-762.

[50] J. Shi, X. Wei, and W. Zhu, "An efficient algorithm for energy management in wireless sensor networks via employing multiple mobile sinks," International Journal of Distributed Sensor Networks, vol. 12, no. 1, p. 3179587, 2016

[51] S. S. Bhunia, J. Pal, and N. Mukherjee, "Fuzzy assisted event driven data collection from sensor nodes in sensor-cloud infrastructure," in 2014 14th IEEE/ACM International Symposium on Cluster, Cloud and Grid Computing. IEEE, 2014, pp. 635-640.

[52] K. Guravaiah and R. L. Velusamy, "Rfdmrp: River formation dynamics based multi-hop routing protocol for data collection in wireless sensor networks," Procedia Computer Science, vol. 54, pp. 31-36, 2015.

[53] Q. Zhang and A. Liu, "An unequal redundancy level-based mechanism for reliable data collection in wireless sensor networks," EURASIP Journal on Wireless Communications and Networking, vol. 2016, no. 1, p. 258,2016

[54] S. M. A. Akber, I. A. Khan, S. S. Muhammad, S. M. Mohsin, I. A. Khan, S. Shamshirband, and A. T. Chronopoulos, "Data volume based data gathering in wsns using mobile data collector," in Proceedings of the 22nd International Database Engineering \& Applications Symposium, 2018, pp. 199-207.

[55] B. Kang, P. Nguyen, and H. Choo, "Delay-efficient energy-minimized data collection with dynamic traffic in wsns," IEEE Sensors Journal, vol. 18, no. 7, pp. 3028-3038, 2018.

[56] M. Hasnain, M. H. Malik, and M. E. Aydin, "An adaptive opportunistic routing scheme for reliable data delivery in wsns," in Proceedings of the 2nd International Conference on Future Networks and Distributed Systems, 2018, pp. 1-7.

[57] P. Zhang, J. Wang, and K. Guo, "Compressive sensing and random walk based data collection in wireless sensor networks," Computer Communications, vol. 129, pp. 43-53, 2018.

[58] S. Chen, S. Zhang, X. Zheng, and X. Ruan, "Layered adaptive compression design for efficient data collection in industrial wireless sensor networks," Journal of Network and Computer Applications, vol. 129, pp. $37-45,2019$.

[59] U. Ullah, A. Khan, M. Zareei, I. Ali, H. A. Khattak, and I. U. Din, "Energy-effective cooperative and reliable delivery routing protocols for underwater wireless sensor networks," Energies, vol. 12, no. 13, p. 2630, 2019.

[60] A. Das and D. Dutta, "Data acquisition in multiple-sink sensor networks," ACM SIGMOBILE Mobile Computing and Communications Review, vol. 9, no. 3, pp. 82-85, 2005.

[61] E. I. Oyman and C. Ersoy, "Multiple sink network design problem in large scale wireless sensor networks," in 2004 IEEE International Conference on Communications (IEEE Cat. No. 04CH37577), vol. 6. IEEE, 2004, pp. 3663-3667.

[62] Z. Vincze, R. Vida, and A. Vidacs, "Deploying multiple sinks in multihop wireless sensor networks," in IEEE international conference on pervasive services. IEEE, 2007, pp. 55-63.

[63] R. Deng, S. He, and J. Chen, "Near-optimal online algorithm for data collection by multiple sinks in wireless sensor networks," in 2014 IEEE International Conference on Communications (ICC). IEEE, 2014, pp 2803-2808

[64] _ - "An online algorithm for data collection by multiple sinks in wireless-sensor networks," IEEE Transactions on Control of Network Systems, vol. 5, no. 1, pp. 93-104, 2016.
[65] R. Wohlers, N. Trigoni, R. Zhang, and S. Ellwood, "Twinroute: Energyefficient data collection in fixed sensor networks with mobile sinks," in 2009 Tenth International Conference on Mobile Data Management: Systems, Services and Middleware. IEEE, 2009, pp. 192-201.

[66] B. Kusy, H. Lee, M. Wicke, N. Milosavljevic, and L. Guibas, "Predictive qos routing to mobile sinks in wireless sensor networks," in 2009 International Conference on Information Processing in Sensor Networks. IEEE, 2009, pp. 109-120.

[67] H. Lee, M. Wicke, B. Kusy, O. Gnawali, and L. Guibas, "Data stashing: energy-efficient information delivery to mobile sinks through trajectory prediction," in Proceedings of the 9th ACM/IEEE International Conference on Information Processing in Sensor Networks, 2010, pp. 291-302.

[68] Z. Li, M. Li, J. Wang, and Z. Cao, "Ubiquitous data collection for mobile users in wireless sensor networks," in 2011 Proceedings IEEE INFOCOM. IEEE, 2011, pp. 2246-2254.

[69] C.-F. Cheng and C.-F. Yu, "Data gathering in wireless sensor networks: A combine-tsp-reduce approach," IEEE Transactions on Vehicular Technology, vol. 65, no. 4, pp. 2309-2324, 2015.

[70] J. Du, H. Wang, Y. Wu, F. Jiang, and H. Huang, "A data collection approach based on mobile sinks for heterogeneous sensor networks," in 2016 8th International Conference on Wireless Communications \& Signal Processing (WCSP). IEEE, 2016, pp. 1-6.

[71] M. V. Shrirame and S. Mini, "Path planning for mobile sink in wireless sensor networks," in 2017 Ninth International Conference on Advanced Computing (ICoAC). IEEE, 2017, pp. 71-76.

[72] F. Tashtarian, K. Sohraby, and A. Varasteh, "Multihop data gathering in wireless sensor networks with a mobile sink," International Journal of Communication Systems, vol. 30, no. 12, p. e3264, 2017.

[73] Y.-H. Yang, T. Lin, B.-H. Liu, S.-I. Chu, C.-Y. Lien, and V.-T. Pham, "An efficient mobile sink scheduling method for data collection in wireless sensor networks," in 2017 International Conference on System Science and Engineering (ICSSE). IEEE, 2017, pp. 554-557.

[74] C.-F. Cheng, S.-L. Lin, C.-C. Wang, and H. Li, "Trail-based routing algorithms for wsns with uncontrolled sink mobility," Computer Communications, vol. 106, pp. 57-74, 2017.

[75] W. Wen, Z. Dong, G. Chen, S. Zhao, and C.-Y. Chang, "Energy efficient data collection scheme in mobile wireless sensor networks," in 2017 31 st International Conference on Advanced Information Networking and Applications Workshops (WAINA). IEEE, 2017, pp. 226-230.

[76] E.-J. Kim, H. H. Choi, and J.-H. Kwon, "Regional density-aware data collection using unmanned aerial vehicle in large-scale wireless sensor networks," Sensors and Materials, vol. 30, no. 8, pp. 1735-1742, 2018.

[77] C. Zhu, X. Long, G. Han, J. Jiang, and S. Zhang, "A virtual gridbased real-time data collection algorithm for industrial wireless sensor networks," EURASIP Journal on Wireless Communications and Networking, vol. 2018, no. 1, p. 134, 2018.

[78] D. J. H. Bell and D. J. S. Asir, "Delay performance analysis of wireless sensor network with multiple mobile sinks," in 2017 IEEE International Conference on Electrical, Instrumentation and Communication Engineering (ICEICE). IEEE, 2017, pp. 1-6.

[79] G. Xie, K. Ota, M. Dong, F. Pan, and A. Liu, "Energy-efficient routing for mobile data collectors in wireless sensor networks with obstacles," Peer-to-Peer Networking and Applications, vol. 10, no. 3, pp. 472-483, 2017.

[80] P. Zhong and F. Ruan, "An energy efficient multiple mobile sinks based routing algorithm for wireless sensor networks," in IOP Conference Series: Materials Science and Engineering, vol. 323, no. 1. IOP Publishing, 2018, p. 012029.

[81] M. Usman, M. A. Jan, X. He, and J. Chen, "A mobile multimedia data collection scheme for secured wireless multimedia sensor networks," IEEE Transactions on Network Science and Engineering, 2018.

[82] V. Kumar and A. Kumar, "Improving reporting delay and lifetime of a wsn using controlled mobile sinks," Journal of Ambient Intelligence and Humanized Computing, vol. 10, no. 4, pp. 1433-1441, 2019.

[83] P. Radoglou-Grammatikis, P. Sarigiannidis, T. Lagkas, and I. Moscholios, "A compilation of uav applications for precision agriculture," Computer Networks, vol. 172, p. 107148, 2020.

[84] M. M. Saleh, "Wsns and iot their challenges and applications for healthcare and agriculture: A survey," Iraqi Journal for Electrical And Electronic Engineering, no. 3RD, pp. 37-43, 2020.

[85] S. Chatterjee, S. Sarkar, and S. Misra, "Energy-efficient data transmission in sensor-cloud," in 2015 Applications and Innovations in Mobile Computing (AIMoC). IEEE, 2015, pp. 68-73. 
[86] S. Songar and R. A. Uthra, "Data gathering through wireless sensor network in cloud," International Journal of Innovative Science, Engineering and Technology, vol. 2, no. 4, pp. 2-5, 2015.

[87] Y. Li, T. Wang, G. Wang, J. Liang, and H. Chen, "Efficient data collection in sensor-cloud system with multiple mobile sinks," in Asia-Pacific Services Computing Conference. Springer, 2016, pp. 130-143.

[88] A. Capponi, C. Fiandrino, D. Kliazovich, P. Bouvry, and S. Giordano, "A cost-effective distributed framework for data collection in cloud-based mobile crowd sensing architectures," IEEE Transactions on Sustainable Computing, vol. 2, no. 1, pp. 3-16, 2017.

[89] T. Wang, Y. Li, G. Wang, J. Cao, M. Z. A. Bhuiyan, and W. Jia, "Sustainable and efficient data collection from wsns to cloud," IEEE Transactions on Sustainable Computing, 2017.

[90] S. Chen, L. Du, K. Wang, and W. Lu, "Fog computing based optimized compressive data collection for big sensory data," in 2018 IEEE International Conference on Communications (ICC). IEEE, 2018, pp. 1-6.

[91] C. Zhu, V. C. Leung, K. Wang, L. T. Yang, and Y. Zhang, "Multi-method data delivery for green sensor-cloud," IEEE Communications Magazine, vol. 55, no. 5, pp. 176-182, 2017.

[92] C. Cecchinel, M. Jimenez, S. Mosser, and M. Riveill, "An architecture to support the collection of big data in the internet of things," in 2014 IEEE World Congress on Services. IEEE, 2014, pp. 442-449.

[93] F. Shi, U. Adeel, E. Theodoridis, M. Haghighi, and J. McCann, "Oppnet: Enabling citizen-centric urban iot data collection through opportunistic connectivity service," in 2016 IEEE 3rd World Forum on Internet of Things (WF-IoT). IEEE, 2016, pp. 723-728.

[94] Q. Zhu, M. Y. S. Uddin, Z. Qin, and N. Venkatasubramanian, "Data collection and upload under dynamicity in smart community internetof-things deployments," Pervasive and Mobile Computing, vol. 42, pp. 166-186, 2017.

[95] Q. Fan and N. Ansari, "Towards workload balancing in fog computing empowered iot," IEEE Transactions on Network Science and Engineering, 2018.

[96] E. Luo, M. Z. A. Bhuiyan, G. Wang, M. A. Rahman, J. Wu, and M. Atiquzzaman, "Privacyprotector: Privacy-protected patient data collection in iot-based healthcare systems," IEEE Communications Magazine, vol. 56, no. 2, pp. 163-168, 2018.

[97] M. Usman, M. A. Jan, X. He, and J. Chen, "P2dca: A privacy-preservingbased data collection and analysis framework for iomt applications," IEEE Journal on Selected Areas in Communications, vol. 37, no. 6, pp. 1222-1230, 2019.

[98] S. Goudarzi, N. Kama, M. H. Anisi, S. Zeadally, and S. Mumtaz, "Data collection using unmanned aerial vehicles for internet of things platforms," Computers \& Electrical Engineering, vol. 75, pp. 1-15, 2019.

[99] T. Wala, N. Chand, and A. K. Sharma, "Energy efficient data collection in smart cities using iot," in Handbook of Wireless Sensor Networks: Issues and Challenges in Current Scenario's. Springer, 2020, pp. 632-654.

[100] K. Sindhanaiselvan and T. Mekala, "A survey on sensor cloud: architecture and applications," International journal of P2P network trends and technology (IJPTT), vol. 6, pp. 49-53, 2014.

[101] M. Baktashmotlagh, A. Bigdeli, and B. C. Lovell, "Dynamic resource aware sensor networks: Integration of sensor cloud and erps," in 2011 8th IEEE International Conference on Advanced Video and Signal Based Surveillance (AVSS). IEEE, 2011, pp. 455-460. 